\title{
Significant Reduction of Interfacial Thermal Resistance and Phonon Scattering in Graphene/Polyimide Thermally Conductive Composite Films for Thermal Management
}

\author{
Kunpeng Ruan, ${ }^{1}$ Yongqiang Guo, ${ }^{1}$ Chuyao $\mathrm{Lu}^{2}$ Xuetao Shi, ${ }^{1}$ Tengbo $\mathrm{Ma},{ }^{1}$ Yali Zhang, \\ Jie Kong, ${ }^{1}$ and Junwei Gu ${ }^{1}{ }^{1}$ \\ ${ }^{1}$ MOE Key Laboratory of Material Physics and Chemistry under Extraordinary Conditions, Shaanxi Key Laboratory of \\ Macromolecular Science and Technology, School of Chemistry and Chemical Engineering, Northwestern Polytechnical University, \\ Xi'an, Shaanxi 710072, China \\ ${ }^{2}$ Queen Mary University of London Engineering School, Northwestern Polytechnical University, Xi'an, Shaanxi 710072, China
}

Correspondence should be addressed to Junwei Gu; gjw@nwpu.edu.cn

Received 13 December 2020; Accepted 2 February 2021; Published 23 February 2021

Copyright ( 2021 Kunpeng Ruan et al. Exclusive Licensee Science and Technology Review Publishing House. Distributed under a Creative Commons Attribution License (CC BY 4.0).

\begin{abstract}
The developing flexible electronic equipment are greatly affected by the rapid accumulation of heat, which is urgent to be solved by thermally conductive polymer composite films. However, the interfacial thermal resistance (ITR) and the phonon scattering at the interfaces are the main bottlenecks limiting the rapid and efficient improvement of thermal conductivity coefficients $(\lambda)$ of the polymer composite films. Moreover, few researches were focused on characterizing ITR and phonon scattering in thermally conductive polymer composite films. In this paper, graphene oxide $(\mathrm{GO})$ was aminated $\left(\mathrm{NH}_{2}-\mathrm{GO}\right)$ and reduced $\left(\mathrm{NH}_{2}-\mathrm{rGO}\right)$, then $\mathrm{NH}_{2}-\mathrm{rGO}$ /polyimide $\left(\mathrm{NH}_{2}-\mathrm{rGO} / \mathrm{PI}\right)$ thermally conductive composite films were fabricated. Raman spectroscopy was utilized to innovatively characterize phonon scattering and ITR at the interfaces in $\mathrm{NH}_{2}$-rGO/PI thermally conductive composite films, revealing the interfacial thermal conduction mechanism, proving that the amination optimized the interfaces between $\mathrm{NH}_{2}-\mathrm{rGO}$ and $\mathrm{PI}$, reduced phonon scattering and ITR, and ultimately improved the interfacial thermal conduction. The in-plane $\lambda\left(\lambda_{\|}\right)$and through-plane $\lambda\left(\lambda_{\perp}\right)$ of $15 \mathrm{wt} \% \mathrm{NH}_{2}$-rGO/PI thermally conductive composite films at room temperature were, respectively, $7.13 \mathrm{~W} / \mathrm{mK}$ and $0.74 \mathrm{~W} / \mathrm{mK}, 8.2$ times $\lambda_{\|}(0.87 \mathrm{~W} / \mathrm{mK})$ and 3.5 times $\lambda_{\perp}(0.21 \mathrm{~W} / \mathrm{mK})$ of pure PI film, also significantly higher than $\lambda_{\|}(5.50 \mathrm{~W} / \mathrm{mK})$ and $\lambda_{\perp}(0.62 \mathrm{~W} / \mathrm{mK})$ of $15 \mathrm{wt} \% \mathrm{rGO} / \mathrm{PI}$ thermally conductive composite films. Calculation based on the effective medium theory model proved that ITR was reduced via the amination of rGO. Infrared thermal imaging and finite element simulation showed that $\mathrm{NH}_{2}-\mathrm{rGO} / \mathrm{PI}$ thermally conductive composite films obtained excellent heat dissipation and efficient thermal management capabilities on the light-emitting diodes bulbs, 5G high-power chips, and other electronic equipment, which are easy to generate heat severely.
\end{abstract}

\section{Introduction}

Flexible electronic equipment are developing rapidly in the directions of high-power, high-density, and highintegration with the advent of the $5 \mathrm{G}$ era $[1,2]$. The technical integration of high-power chips, wireless charging, and Bluetooth has caused severe heat generation in flexible electronic equipment, seriously affecting the stability, reliability, and service life $[3,4]$. Polyimide (PI) is a kind of polymer material with excellent comprehensive properties and various advantages such as low thermal expansion coefficient, high flexibility, high resistance to high and low temperatures, high radiation resistance, and high chemical stability [5-7]. It is widely used in flexible electronic displays, organic lightemitting diodes (LEDs), thin-film solar panels, and other flexible electronic equipment $[8,9]$. However, the intrinsic low thermal conductivity coefficient $(\lambda)$ of PI cannot meet the current requirements for efficient and fast heat dissipation of flexible displays, folding screens, and flexible wearable devices, etc. $[10,11]$.

In recent years, researchers have used graphene [12], carbon nanotubes (CNT) [13], boron nitride (BN) [14], aluminum nitride (AlN) [15], etc. as thermally conductive fillers to prepare thermally conductive PI-based composite films 
by solution blending followed by blade coating. Wang et al. [16] prepared carbon nitride nanosheets/PI (CNNS/PI) thermally conductive composite films by "solution blendingblade coating" technology. When the amount of CNNS was $20 \mathrm{wt} \%$, the corresponding in-plane $\lambda\left(\lambda_{\|}\right)$and throughplane $\lambda\left(\lambda_{\perp}\right)$ of the CNNS/PI thermally conductive composite films reached $2.04 \mathrm{~W} / \mathrm{mK}$ and $0.32 \mathrm{~W} / \mathrm{mK}$, respectively. Song et al. [17] fabricated BN/AlN/PI thermally conductive composite films via "solution blending-blade coating." The $\lambda_{\|}$ and $\lambda_{\perp}$ of the BN/AlN/PI thermally conductive composite films, respectively, reached $4.09 \mathrm{~W} / \mathrm{mK}$ and $0.44 \mathrm{~W} / \mathrm{mK}$ when the weight ratio of $\mathrm{BN}$ to AlN was $1: 1$ and the total amount was $30 \mathrm{wt} \%$.

However, the reported $\lambda$ values of thermally conductive PI-based composite films are still far from expectation $[18,19]$. One of the most important bottlenecks lies in the inherent interfaces between phases and the high interfacial thermal resistance (ITR) [20], which largely limits the efficiency of improvement for $\lambda$ of thermally conductive composite films [21]. The intrinsic mechanism is that the heat flow will be hindered to a certain extent when passing through the interfaces, and severe heat loss will occur, usually manifested as a sudden drop in temperatures at the interfaces [22]. This is mainly because phonon will scatter severely at the interfaces due to vibration harmonic mismatch, acoustic mismatch, and modulus mismatch during the heat transfer process, and the mean free path of phonon will decrease significantly [23], which is not conducive to the rapid and efficient improvement for $\lambda$ of thermally conductive composite films [24]. Therefore, researchers have been struggling to explore suitable methods to effectively improve the interfaces between the polymer matrix and the thermally conductive fillers, so as to reduce the ITR and the phonon scattering at the interfaces [25-27]. Tseng et al. [28] used glycidyl methacrylate (GMA) to graft-modify graphene oxide ( $g$-GO) to prepare $g-\mathrm{GO} / \mathrm{PI}$ thermally conductive composite films. When the amount of $g$-GO was $10 \mathrm{wt} \%$, the corresponding $\lambda_{\|}$of $g$-GO/PI thermally conductive composite films was $0.81 \mathrm{~W} / \mathrm{mK}$, significantly higher than that of GO/PI thermally conductive composite films $(0.32 \mathrm{~W} / \mathrm{mK})$ with the same amount of fillers. The main reason is that GMA improved the interfacial compatibility between $g$-GO and PI matrix and reduced the ITR. In our previous work [29], polydopamine (PDA) was performed to functionalize the surface of boron nitride nanosheets (BNNS@PDA), and BNNS@PDA/aramid nanofiber (BNNS@PDA/ANF) thermally conductive composite paper was prepared via vacuum-assisted filtration followed by hot pressing. When the amount of BNNS@PDA was $50 w t \%$, the $\lambda_{\|}$and $\lambda_{\perp}$ of BNNS@PDA/ANF thermally conductive composite paper reached $3.94 \mathrm{~W} / \mathrm{mK}$ and $0.62 \mathrm{~W} / \mathrm{mK}$, respectively, which were significantly higher than $\lambda_{\|}(3.33 \mathrm{~W} / \mathrm{mK})$ and $\lambda_{\perp}$ $(0.52 \mathrm{~W} / \mathrm{mK})$ of BNNS/ANF thermally conductive composite paper with the same amount of fillers, due to the hydrogen bonds that improved the interfacial compatibility between BNNS@PDA and ANF.

Although many researchers have tried to improve the interfaces between the thermally conductive fillers and the polymer matrix, most of the studies only use the improve- ment of $\lambda$ to indirectly characterize the improvement effect of the interfaces $[30,31]$. Targeted and detailed researches on ITR and phonon scattering are still in lack [32]. It is acknowledged that Raman spectroscopy can reflect the vibration and rotation of molecules and can reflect the phonon vibration mode, which can be used to characterize the thermal conduction and the degree of phonon scattering at the interfaces [33, 34]. Yue et al. [35] used Raman spectroscopy to study the thermal conduction property of the interfaces between molybdenum disulfide $\left(\mathrm{MoS}_{2}\right)$ and silica $\left(\mathrm{SiO}_{2}\right)$ as well as that between $\mathrm{MoS}_{2}$ and graphene, respectively, finding that the thermal conduction property of the interfaces between $\mathrm{MoS}_{2}$ and graphene was significantly better than $\mathrm{MoS}_{2} / \mathrm{SiO}_{2}$, because graphene obtains higher $\lambda$ than $\mathrm{SiO}_{2}$, and the heat at the interfaces can be transferred more efficiently. Qiu et al. [36] modified gold ( $\mathrm{Au}$ ) nanoparticles on the surfaces of CNTs by chemical vapor deposition (CVD) and used Raman spectroscopy to study the thermal conduction property of the interfaces between CNTs before and after modification. Results showed that the surface modification by $\mathrm{Au}$ nanoparticles improved the interfaces between CNTs and effectively reduced phonon scattering at the interfaces.

Currently, Raman spectroscopy is mostly used to study the interfacial thermal conduction properties between inorganics $[37,38]$. As far as we know, few researchers have utilized Raman spectroscopy to study the interfacial thermal conduction properties such as ITR and phonon scattering in thermally conductive polymer composite films. This paper is aimed at optimizing the interfaces between reduced graphene oxide (rGO) and PI, and then Raman spectroscopy is innovatively performed to conduct the targeted and detailed investigation on phonon scattering and ITR in the thermally conductive PI-based composite films, revealing the interfacial thermal conduction mechanism. Graphene oxide (GO) was firstly aminated by urea melt $\left(\mathrm{NH}_{2}-\mathrm{GO}\right)$, then reduced $\left(\mathrm{NH}_{2}-\mathrm{rGO}\right)$, and then $\mathrm{NH}_{2}-\mathrm{rGO} / \mathrm{PI}$ thermally conductive composite films were fabricated via "in-situ polymerizationblade coating-thermal imidization" technology. X-ray photoelectron spectroscopy (XPS), Fourier transform infrared (FTIR) spectroscopy, thermogravimetric analysis (TGA), Raman spectroscopy, X-ray diffraction (XRD), and atomic force microscope (AFM) were all performed to analyze and characterize the $\mathrm{NH}_{2}$-rGO thermally conductive fillers. Raman spectroscopy was performed to characterize the phonon scattering and ITR at the interfaces in the $\mathrm{NH}_{2}$-rGO/PI thermally conductive composite films, revealing the thermal conduction mechanism at the interfaces. On this basis, the influences of the amount of $\mathrm{NH}_{2}$-rGO thermally conductive fillers, ambient temperature and amination on the $\lambda$, and mechanical properties and thermal properties of the $\mathrm{NH}_{2}$ rGO/PI thermally conductive composite films were analyzed and studied in detail.

\section{Results and Discussion}

The process of preparing $\mathrm{NH}_{2}$-rGO thermally conductive fillers and fabricating $\mathrm{NH}_{2}-\mathrm{rGO} / \mathrm{PI}$ thermally conductive composite films is shown in Figure 1. The modified Hummers method was used to oxidize the graphite nanoplatelets 


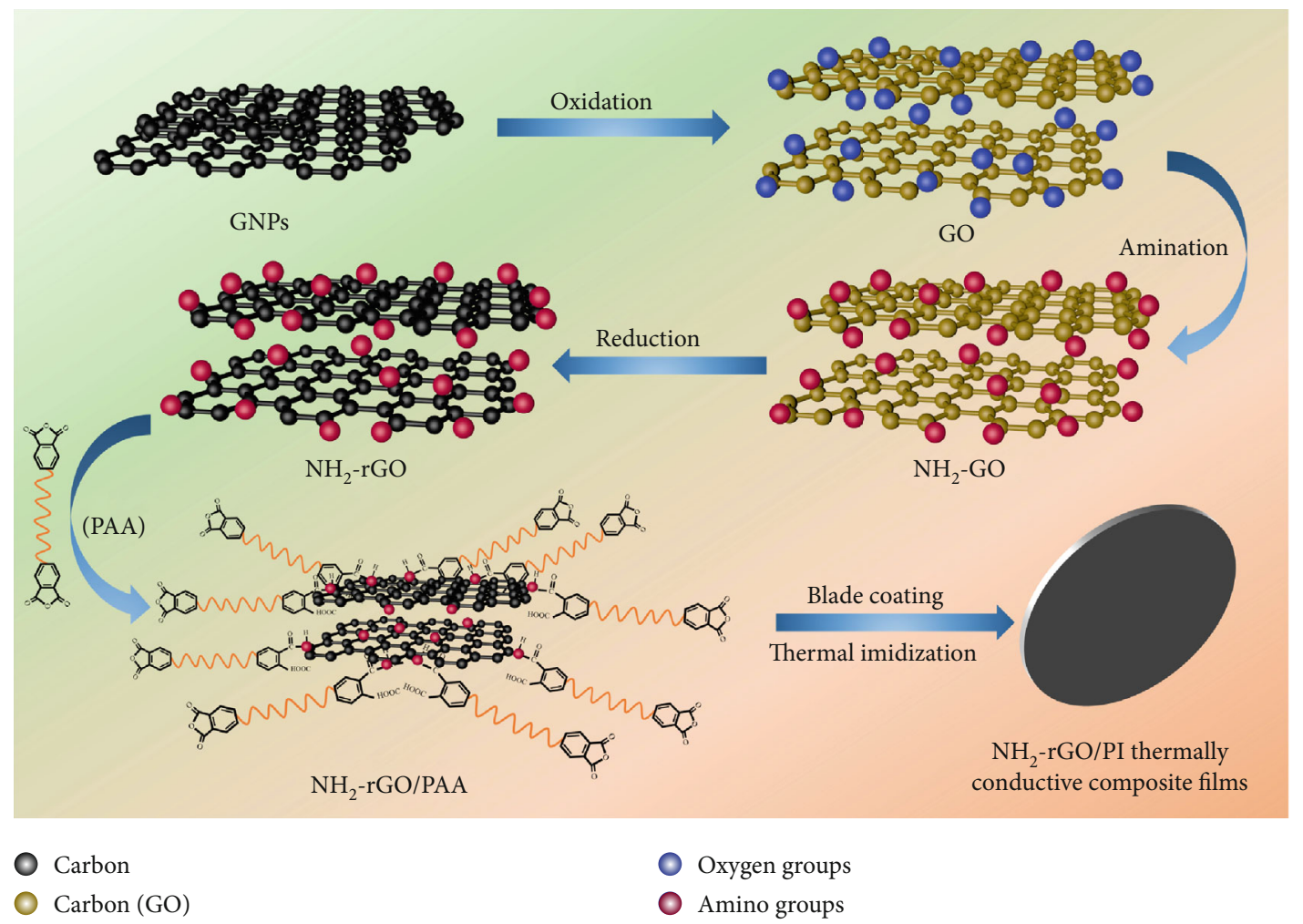

Figure 1: Schematic diagram of preparing $\mathrm{NH}_{2}$-rGO thermally conductive fillers and fabricating $\mathrm{NH}_{2}$-rGO/PI thermally conductive composite films.

(GNPs) to prepare GO, then GO was aminated with urea melt $\left(\mathrm{NH}_{2}-\mathrm{GO}\right)$, and then $\mathrm{NH}_{2}$-rGO was prepared by thermal reduction. A certain amount of $\mathrm{NH}_{2}-\mathrm{rGO}$ was in situ introduced into polyamide acid (PAA), then the amino groups of $\mathrm{NH}_{2}$-rGO and the acid anhydride groups at the end of the PAA chains underwent the interfacial chemical reaction, and the two were connected by $\mathrm{C}-\mathrm{N}-\mathrm{C}$ bonds at the interfaces to improve the interfacial properties. Finally, $\mathrm{NH}_{2}$-rGO/PAA solution was blade-coated into films and subjected to gradient thermal imidization to prepare the $\mathrm{NH}_{2}$-rGO/PI thermally conductive composite films. The experimental details can be found in Supplementary 1 .

Figure 2(a) shows the XPS full spectra of GNPs, GO, $\mathrm{NH}_{2}-\mathrm{GO}$, and $\mathrm{NH}_{2}-\mathrm{rGO}$. The molar fraction of surface elements and carbon/oxygen $(\mathrm{C} / \mathrm{O})$ atomic ratio are shown in Table S1. There are only two kinds of elements, $\mathrm{C}$ and $\mathrm{O}$, in GNPs, with the $\mathrm{C} / \mathrm{O}$ atomic ratio of 26.03 . Compared to GNPs, the $\mathrm{C} / \mathrm{O}$ atomic ratio of $\mathrm{GO}$ decreases to 10.49 , which is mainly due to the oxidation of GNPs and that more oxygen-containing functional groups (such as hydroxyl, carboxyl, etc.) are introduced. The characteristic peaks of nitride $(\mathrm{N})$ appear in the XPS spectra of $\mathrm{NH}_{2}-\mathrm{GO}$ and $\mathrm{NH}_{2}-\mathrm{rGO}$, and the $\mathrm{C} / \mathrm{O}$ atomic ratios are 10.98 and 16.44 , respectively. It shows that the amination is successfully performed on GO, and amino groups remain well after thermal reduction. From $\mathrm{NH}_{2}-\mathrm{GO}$ to $\mathrm{NH}_{2}-\mathrm{rGO}$, the molar fraction of $\mathrm{N}$ increases from $3.72 \%$ to $5.62 \%$, mainly due to the decrease of oxygen-containing functional groups in $\mathrm{NH}_{2}$ rGO [39].
In order to further prove that the $\mathrm{N}$ element is chemically bonded to the surface of rGO, the XPS narrow spectra of C $1 \mathrm{~s}$ and $\mathrm{N} 1 \mathrm{~s}$ are peak-fitted. Figure 2(b) is the XPS narrow spectrum of $\mathrm{C} 1 \mathrm{~s}$. The peak of $\mathrm{C} 1 \mathrm{~s}$ of $\mathrm{GO}$ can be fitted to three Lorentz peaks, corresponding to C-C $(284.5 \mathrm{eV}), \mathrm{C}-\mathrm{O}$ $(286.5 \mathrm{eV})$, and $\mathrm{C}=\mathrm{O}(287.3 \mathrm{eV})$. The $\mathrm{C} 1 \mathrm{~s}$ peaks of $\mathrm{NH}_{2}-\mathrm{GO}$ and $\mathrm{NH}_{2}-\mathrm{rGO}$ can also be fitted to three Lorentz peaks, corresponding to $\mathrm{C}-\mathrm{C}(284.6 \mathrm{eV}), \mathrm{C}-\mathrm{O}(285.4 \mathrm{eV})$, and $\mathrm{N}-\mathrm{C}=\mathrm{O}(289.1 \mathrm{eV})$. Figure $2(\mathrm{c})$ exhibits the XPS narrow spectrum of $\mathrm{N} 1 \mathrm{~s}$. The peaks of $\mathrm{N} 1 \mathrm{~s}$ of $\mathrm{NH}_{2}-\mathrm{GO}$ and $\mathrm{NH}_{2}-\mathrm{rGO}$ can be fitted to three Lorentz peaks, corresponding to $-\mathrm{NH}_{2}$ (398.9 eV), C-N-C (399.6 eV), and -CO-NH- (400.4 eV) [40]. The peak fitting of XPS narrow spectrum proves that the amino groups are successfully grafted onto the surface of GO and $\mathrm{rGO}$ by chemical bonding.

Figure $2(\mathrm{~d})$ is the FTIR spectra of GNPs, GO, $\mathrm{NH}_{2}-\mathrm{GO}$, and $\mathrm{NH}_{2}$-rGO. GNPs present an absorption peak at $1520 \mathrm{~cm}^{-1}$, attributed to carboxyl, because GNPs are slightly oxidized during storage. The newly appeared absorption peaks at $3720 \mathrm{~cm}^{-1}$ and $1300 \mathrm{~cm}^{-1}$ for GO correspond to hydroxyl and ether bond, respectively, due to the successful oxidation process. After amination, $\mathrm{NH}_{2}$-GO presents new absorption peaks at $3610 \mathrm{~cm}^{-1}, 1570 \mathrm{~cm}^{-1}$, and $1250 \mathrm{~cm}^{-1}$, corresponding to amide, primary amine, and $\mathrm{C}-\mathrm{N}-\mathrm{C}$ groups [39]. It is confirmed that the amino groups have been grafted onto GO successfully. After thermal reduction to $\mathrm{NH}_{2}-\mathrm{rGO}$, the absorption peaks of ether bond disappear, hydroxyl, and carboxyl are both weakened, and amide, primary amine, and $\mathrm{C}-\mathrm{N}-\mathrm{C}$ groups still maintain, which proves that $\mathrm{NH}_{2}-\mathrm{GO}$ is 

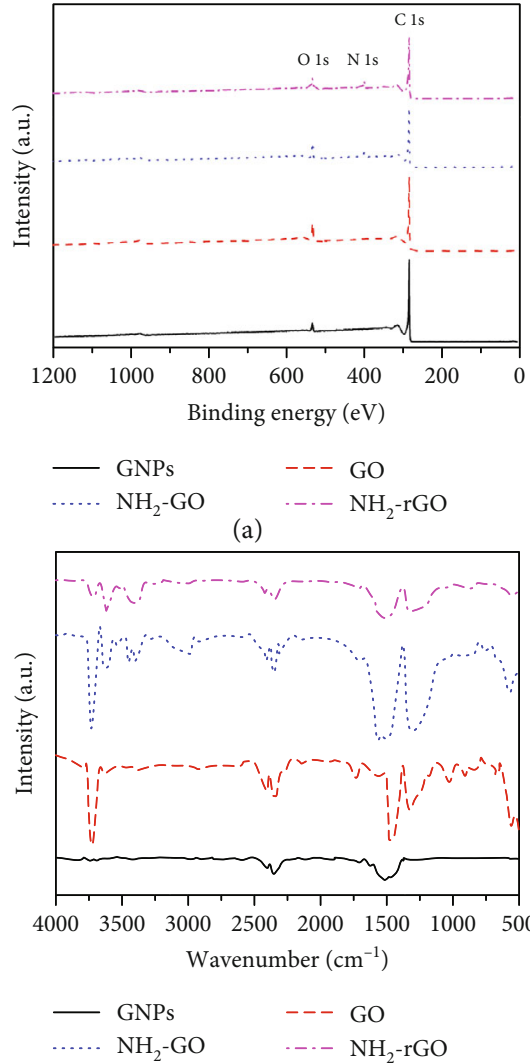

(d)

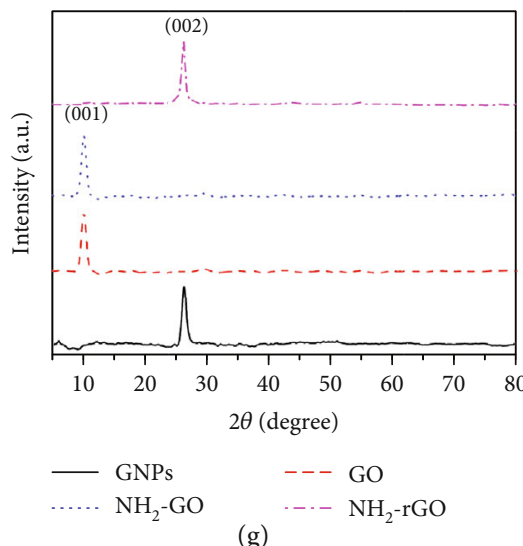

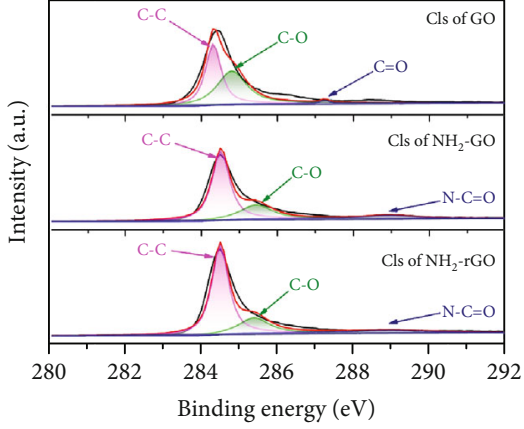

(b)

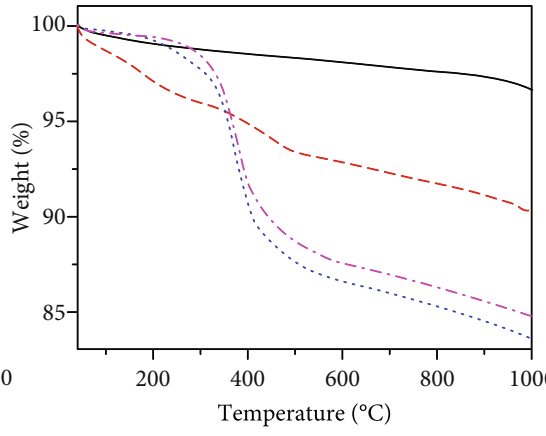

$---\mathrm{GO}$

$\cdot-\cdot-\mathrm{NH}_{2}-\mathrm{rGO}$

(e)

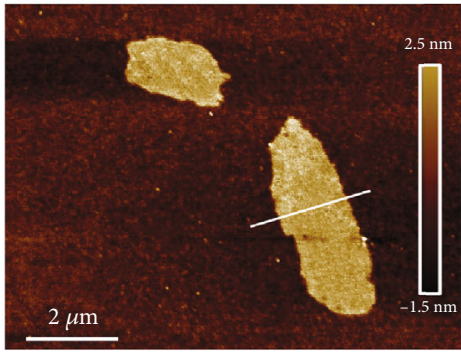

(h)

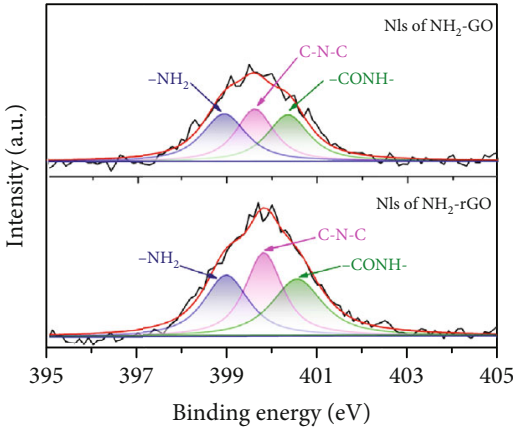

(c)

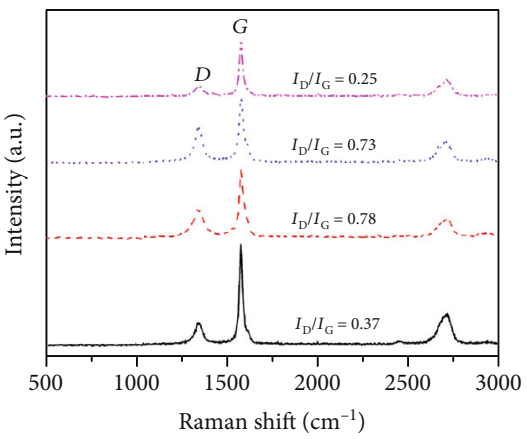

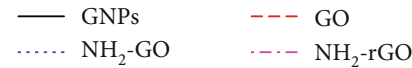

(f)

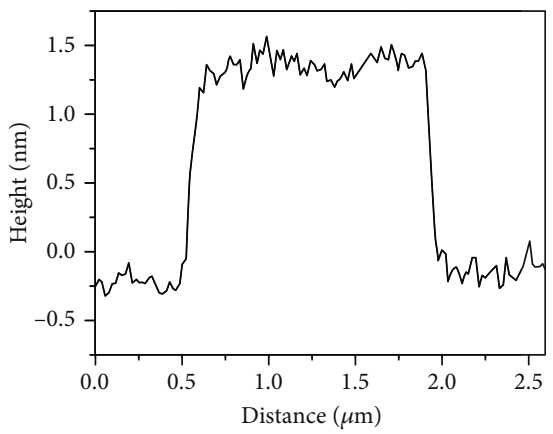

(i)

FIgURE 2: XPS full spectra (a), C $1 \mathrm{~s}$ high solution XPS narrow spectra (b), N $1 \mathrm{~s}$ high solution XPS narrow spectra (c), FTIR spectra (d), TGA curves (e), and Raman spectra (f), XRD patterns (g) of GNPs, GO, $\mathrm{NH}_{2}-\mathrm{GO}$, and $\mathrm{NH}_{2}$-rGO, AFM image (h) and height-distance curve (i) of $\mathrm{NH}_{2}$-rGO.

reduced in oxygen-containing functional groups, and its amino groups are still reserved.

Figure 2(e) exhibits the TGA curves of GNPs, GO, $\mathrm{NH}_{2}-\mathrm{GO}$, and $\mathrm{NH}_{2}-\mathrm{rGO}$. There are no obvious thermal weight loss steps in GNPs, and the thermal weight loss is small, which is attributed to the small amount of oxygencontaining functional groups on the surface of GNPs. Compared with GNPs, GO has a greater degree of thermal weight loss, because GO grafts more oxygen-containing functional groups, whose thermal decomposition causes significant weight loss. Both $\mathrm{NH}_{2}-\mathrm{GO}$ and $\mathrm{NH}_{2}-\mathrm{rGO}$ have an obvious thermal weight loss step during $300 \sim 500^{\circ} \mathrm{C}$, mainly due to the thermal decomposition of amino groups grafted on the surfaces. The thermal weight loss of $\mathrm{NH}_{2}-\mathrm{rGO}$ is smaller than that of $\mathrm{NH}_{2}-\mathrm{GO}$, due to the removal of some oxygencontaining functional groups of $\mathrm{NH}_{2}-\mathrm{GO}$ during the thermal reduction process. In addition, in the range of $40 \sim 140^{\circ} \mathrm{C}, \mathrm{GO}$ shows obvious thermal weight loss while $\mathrm{NH}_{2}-\mathrm{GO}$ does not, which is due to the decomposition of some extremely unstable oxygen-containing functional groups on the surface of 
GO, and those have been removed during the preparation process of $\mathrm{NH}_{2}-\mathrm{GO}$ [41].

Figure 2(f) shows the Raman spectra of GNPs, $\mathrm{GO}, \mathrm{NH}_{2}$ $\mathrm{GO}$, and $\mathrm{NH}_{2}$-rGO. GNPs, GO, $\mathrm{NH}_{2}-\mathrm{GO}$, and $\mathrm{NH}_{2}$-rGO all have strong Raman $\mathrm{D}$ and $\mathrm{G}$ peaks at $1341 \mathrm{~cm}^{-1}$ and $1580 \mathrm{~cm}^{-1}$, which are related to the random vibration of amorphous carbon ( $\mathrm{sp}^{3}$ hybridized carbon) and in-plane vibration of graphitic carbon ( $\mathrm{sp}^{2}$ hybridized carbon) [42]. The intensity ratio of $\mathrm{D}$ and $\mathrm{G}$ peak $\left(I_{D} / I_{G}\right)$ is used to characterize the defect density [43]. The higher the $I_{D} / I_{G}$ value, the more defects in carbon atoms lattice. The corresponding $I_{D} / I_{G}$ value of GNPs (0.37) is low, indicating that there are only a few defects. The $I_{D} / I_{G}$ value of GO increases to 0.78 , which is attributed to the increase in overall randomness and defects during the oxidation process. After amination, the $I_{D} / I_{G}$ value of $\mathrm{NH}_{2}$ - $\mathrm{GO}$ (0.73) decreases slightly, basically the same as that of GO, indicating that the amination does not change the structure of GO. After thermal reduction, the $I_{D} / I_{G}$ value of $\mathrm{NH}_{2}$-rGO $(0.25)$ significantly reduces, indicating that thermal reduction restores the graphite structure, reduces the degree of randomness, and effectively repairs some of the defects introduced by the oxidation process.

Figure 2(g) exhibits XRD patterns of GNPs, GO, $\mathrm{NH}_{2}-\mathrm{GO}$, and $\mathrm{NH}_{2}$-rGO. GNPs present a sharp diffraction peak at about $26^{\circ}$, corresponding to the (002) crystal plane. In contrast, there is only a sharp diffraction peak at about $10^{\circ}$ for GO, corresponding to the (001) crystal plane, due to that the oxidation process disturbs the (002) crystal plane, proving the successful oxidation process. After amination to $\mathrm{NH}_{2}-\mathrm{GO}$, the XRD pattern shows little difference, proving that the amination does not change the crystal forms of GO. After thermal reduction, the (001) crystal plane disappears and the diffraction peak at $26^{\circ}$ corresponding to the (002) crystal plane appears again, proving the successful reduction and that the interplanar spacing is $0.34 \mathrm{~nm}$ [44].

Figures 2(h) and 2(i) are the AFM image and corresponding height-distance curve of $\mathrm{NH}_{2}-\mathrm{rGO}$. The thickness of $\mathrm{NH}_{2}-\mathrm{rGO}$ is uniform, about $1.38 \mathrm{~nm}$ on average. As mentioned above, the interplanar spacing is $0.34 \mathrm{~nm}$. Therefore, the number of layers of $\mathrm{NH}_{2}-\mathrm{rGO}$ is about 4 . It can be inferred that oxidation, amination, and thermal reduction treatments can effectively exfoliate the GNPs and successfully prepare few-layered $\mathrm{NH}_{2}$-rGO thermally conductive fillers.

In order to conduct detailed researches on phonon scattering at the interfaces in $\mathrm{NH}_{2}$-rGO/PI thermally conductive composite films, Raman spectroscopy is innovatively utilized. Figure 3(a) shows the Raman spectrum of $15 \mathrm{wt} \% \mathrm{rGO} / \mathrm{PI}$ and $15 \mathrm{wt} \% \mathrm{NH}_{2}$-rGO/PI thermally conductive composite films under laser power of $1.0 \mathrm{~mW}$, and Figure 3(b) is a partial view. From Figure 3(a), there are five distinct characteristic peaks of $15 \mathrm{wt} \% \mathrm{rGO} / \mathrm{PI}$ thermally conductive composite films. The characteristic peaks at $1370 \mathrm{~cm}^{-1}, 1580 \mathrm{~cm}^{-1}$, $1620 \mathrm{~cm}^{-1}, 1789 \mathrm{~cm}^{-1}$, and $2772 \mathrm{~cm}^{-1}$ correspond to the axial vibration of the $\mathrm{C}-\mathrm{N}-\mathrm{C}$ groups, the $\mathrm{G}$ peak of $\mathrm{rGO}$, the ring vibration of aromatic imide, the asymmetric tensile vibration of the $\mathrm{C}=\mathrm{O}$ groups, and the $2 \mathrm{D}$ peak of $\mathrm{rGO}$ [45]. For $15 \mathrm{wt} \%$ $\mathrm{NH}_{2}$-rGO/PI thermally conductive composite films, the positions of the last four characteristic peaks show no shifts, while the characteristic peak at $1370 \mathrm{~cm}^{-1}$ blue-shifts to
$1378 \mathrm{~cm}^{-1}$ (Figure 3(b)), indicating that the axial vibration of the $\mathrm{C}-\mathrm{N}-\mathrm{C}$ groups in the $\mathrm{NH}_{2}-\mathrm{rGO} / \mathrm{PI}$ thermally conductive composite films is enhanced. This is because the $\mathrm{NH}_{2}-$ rGO fillers and the PI matrix are connected by C-N-C groups, then its vibration is increased. In other words, $\mathrm{NH}_{2}$-rGO and PI form chemical bonds (C-N-C groups) at the interfaces, which causes the phonon tangential mode vibration to increase, enhances the "phonon-electron" interaction, therefore causes the blue-shifts of Raman characteristic peak of C-N-C groups, and reduces phonon scattering at the interfaces as well as ITR, and ultimately promotes the improvement of the thermal conduction at the interfaces [46].

Figure 3(c) shows the Raman peak positions of C-N-C groups in $15 \mathrm{wt} \% \mathrm{rGO} / \mathrm{PI}$ and $15 \mathrm{wt} \% \mathrm{NH}_{2}$-rGO/PI thermally conductive composite films as a function of laser power. The laser power is kept below $2.0 \mathrm{~mW}$ to ensure that the samples will not be damaged. Raman characteristic peaks of C-N-C groups in both the $15 \mathrm{wt} \% \mathrm{rGO} / \mathrm{PI}$ and $\mathrm{NH}_{2}-$ rGO/PI thermally conductive composite films have an obvious red shift with the increase of laser power. When the laser power is increased from $0.2 \mathrm{~mW}$ to $1.8 \mathrm{~mW}$, the characteristic peak of C-N-C groups in $15 \mathrm{wt} \% \mathrm{rGO} / \mathrm{PI}$ thermally conductive composite films is red-shifted from $1372 \mathrm{~cm}^{-1}$ to $1367 \mathrm{~cm}^{-1}$ and that in $15 \mathrm{wt} \% \mathrm{NH}_{2}$-rGO/PI thermally conductive composite films is from $1380 \mathrm{~cm}^{-1}$ to $1376 \mathrm{~cm}^{-1}$. This is because as the laser power increases, the temperature at the interfaces of $\mathrm{rGO}$ (or $\mathrm{NH}_{2}$-rGO) and the PI matrix rises sharply, and the degree of phonon scattering at the interfaces increases sharply, causing the phonon tangential mode vibration to weaken. Next, according to Equation (1) [35], the change trend of Raman peak positions of C-N-C groups in $15 \mathrm{wt} \% \mathrm{rGO} / \mathrm{PI}$ and $15 \mathrm{wt} \% \mathrm{NH}_{2}$-rGO/PI thermally conductive composite films is linearly fitted with laser power. The fitting results are shown in Figure 3(d).

$$
\omega(P)=\omega_{0}+\chi_{P} P,
$$

Among them, $\omega$ is the Raman peak position, $P$ is the laser power, $\chi_{P}$ is the first-order power correlation coefficient, that is, the slope of the fitted straight line, and $\omega_{0}$ is the extrapolated $\omega$ value when $\omega=0$.

It can be seen from Figure 3(c) that the $\chi_{P}$ in the $15 \mathrm{wt} \%$ $\mathrm{NH}_{2}-\mathrm{rGO} / \mathrm{PI}$ thermally conductive composite films is $-2.754 \mathrm{~cm}^{-1} / \mathrm{mW}$, and its absolute value is smaller than that of $\chi_{P}$ in the $15 \mathrm{wt} \% \mathrm{rGO} / \mathrm{PI}$ thermally conductive composite films $\left(-3.083 \mathrm{~cm}^{-1} / \mathrm{mW}\right)$, indicating that the red shift rate of the Raman characteristic peak of the $\mathrm{C}-\mathrm{N}-\mathrm{C}$ groups in the $15 \mathrm{wt} \% \mathrm{NH}_{2}$-rGO/PI thermally conductive composite films is smaller. This is due to the better thermal conduction property of the interfaces between $\mathrm{NH}_{2}-\mathrm{rGO}$ and $\mathrm{PI}$ in the $\mathrm{NH}_{2}$ rGO/PI thermally conductive composite films, which can efficiently conduct the highly generated heat by the laser and weaken the phonon tangential mode vibration and the degree of phonon scattering at the interfaces [47].

Figures S1(a)-S1(c) exhibit the scanning electron microscope (SEM) images of cross-sections for pure PI film, $15 \mathrm{wt} \% \mathrm{rGO} / \mathrm{PI}$ and $15 \mathrm{wt} \% \mathrm{NH}_{2}$-rGO/PI thermally 


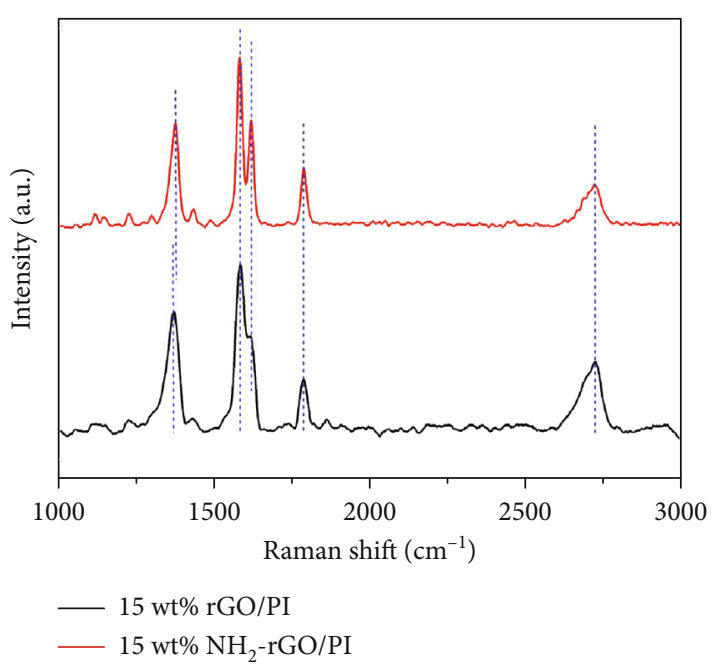

(a)

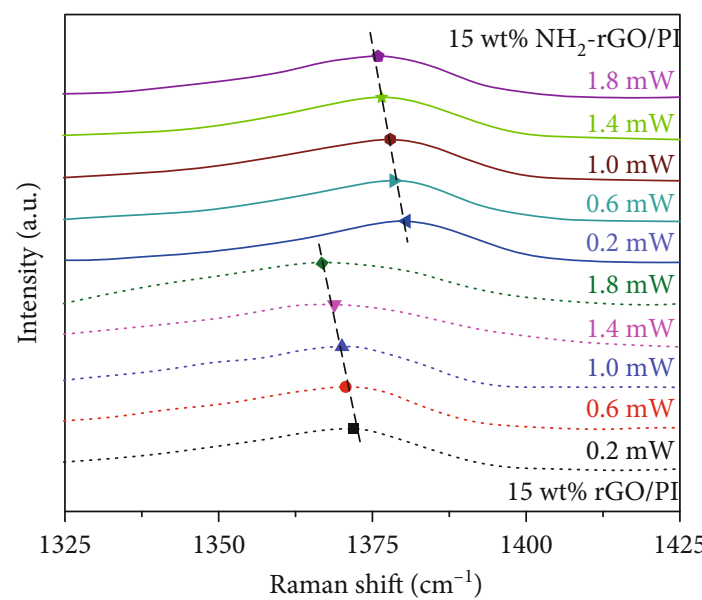

(c)

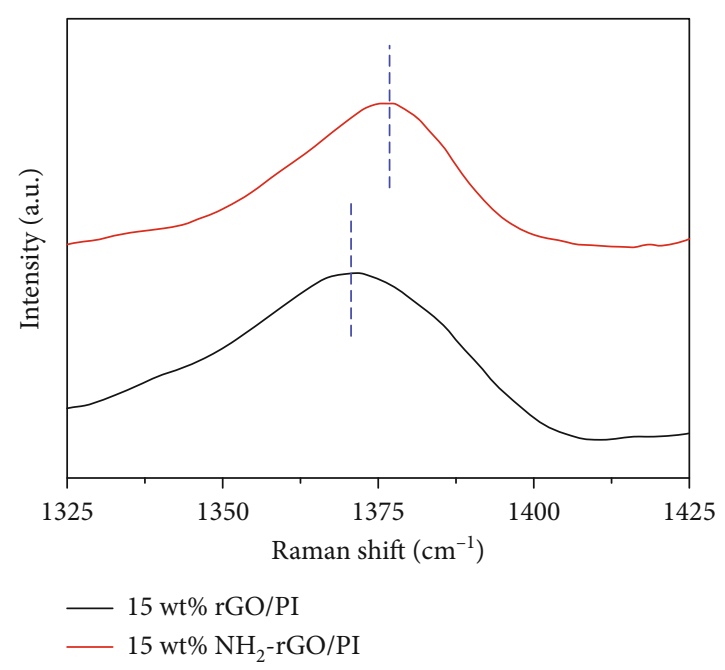

(b)

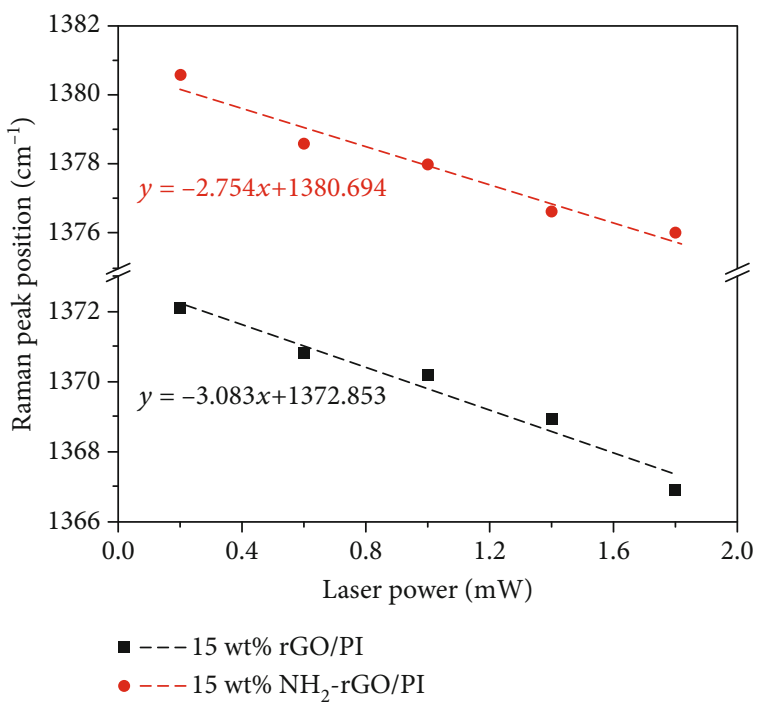

(d)

Figure 3: Raman spectra of $15 \mathrm{wt} \% \mathrm{rGO} / \mathrm{PI}$ (a) and $15 \mathrm{wt} \% \mathrm{NH}_{2}$-rGO/PI (b) thermally conductive composite films with laser power of $1.0 \mathrm{~mW}$. Raman spectra of $15 \mathrm{wt} \% \mathrm{rGO} / \mathrm{PI}$ and $15 \mathrm{wt} \% \mathrm{NH}_{2}-\mathrm{rGO} / \mathrm{PI}$ thermally conductive composite films with increasing laser power (c). Relationship between Raman peak position of the $\mathrm{C}-\mathrm{N}-\mathrm{C}$ group of $15 \mathrm{wt} \% \mathrm{rGO} / \mathrm{PI}$ and $15 \mathrm{wt} \% \mathrm{NH}_{2}$-rGO/PI thermally conductive composite films vs. laser power (d).

conductive composite films, respectively. The cross-section of the pure PI film shows a typical brittle fracture morphology. With the introduction of thermally conductive fillers ( $\mathrm{rGO}$ or $\mathrm{NH}_{2}-\mathrm{rGO}$ ), the morphology of cross-sections changes, and flakes of $\mathrm{rGO}$ or $\mathrm{NH}_{2}-\mathrm{rGO}$ appear around the PI matrix. Moreover, rGO or $\mathrm{NH}_{2}-\mathrm{rGO}$ is basically oriented along the in-plane direction of the PI films. This is due to the blade coating process that promotes the PAA solution to produce the horizontal flow. Driven by the flow forces, rGO or $\mathrm{NH}_{2}-\mathrm{rGO}$ is highly oriented along the in-plane direction of the PI films. Moreover, the agglomeration of rGO is clearly observed while $\mathrm{NH}_{2}$-rGO disperses uniformly due to that the amination process improves the compatibility and thereafter enhances dispersion of thermally conductive fillers in the PI matrix. In addition, there are some defects such as holes in the cross-sections of the rGO/PI thermally conductive composite films as the compatibility between rGO and PI is not good. In contrast, for the cross-sections of the $\mathrm{NH}_{2}$-rGO/PI thermally conductive composite films, $\mathrm{NH}_{2}-\mathrm{rGO}$ is well compatible with PI and there are no defects or holes, which proves that the amination improves the interfacial compatibility between $\mathrm{NH}_{2}-\mathrm{rGO}$ fillers and PI matrix.

It is verified that the amination improves the interfaces between $\mathrm{NH}_{2}-\mathrm{rGO}$ and PI and then optimizes the thermal conduction property of the interfaces. The schematic mechanism is shown in Figure 4. For the rGO/PI thermally conductive composite films, there is no connection between rGO and PI. Because of the great difference of the $\lambda$ and surface properties between rGO and PI, severe phonon vibration 


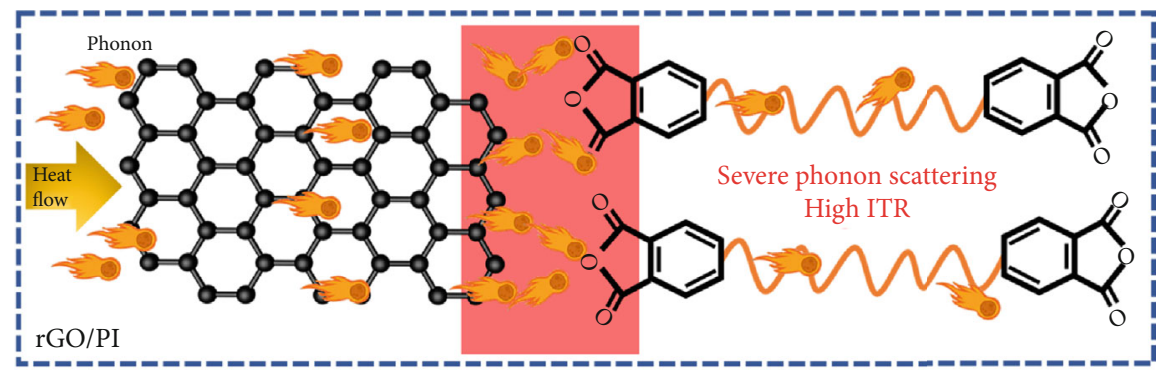

(a)

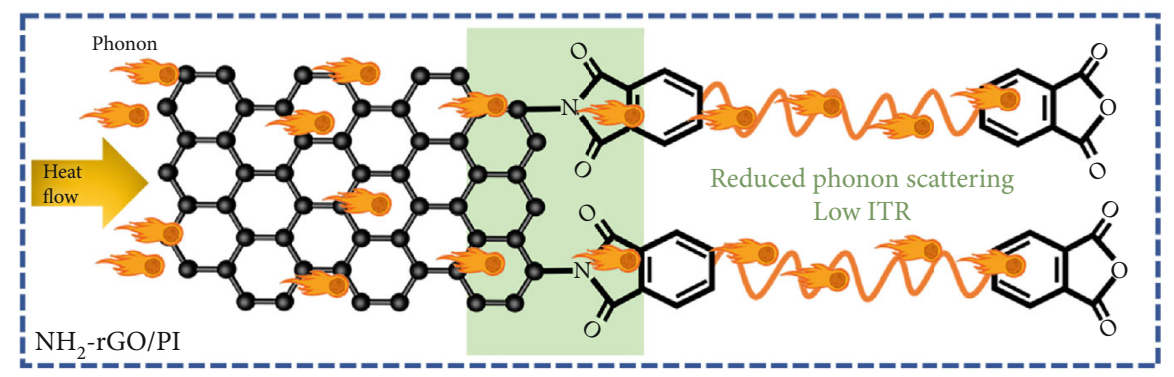

(b)

FIGURE 4: Schematic diagrams of mechanism of interfacial optimization. Schematic diagrams of blocked heat flow, severe phonon scattering, and high ITR at the interfaces in rGO/PI thermally conductive composite films (a). Schematic diagrams of smooth heat flow, reduced phonon scattering, and low ITR at the interfaces in $\mathrm{NH}_{2}$-rGO/PI thermally conductive composite films (b).

harmonic mismatch, acoustic mismatch, and modulus mismatch will occur at the interfaces during the heat transfer process, which causes the phonon to be severely scattered interfacially. Therefore, the mean free path of phonon is shortened, and the heat transfer is severely hindered. Finally, the high ITR is formed, which hinders the rapid improvement of the $\lambda$ of the rGO/PI thermally conductive composite films. For the $\mathrm{NH}_{2}$-rGO/PI thermally conductive composite films, the amino groups of $\mathrm{NH}_{2}-\mathrm{rGO}$ and the acid anhydride group of PAA undergo the interfacial chemical reaction, and the two are connected by $\mathrm{C}-\mathrm{N}-\mathrm{C}$ bonds with high thermal stability, which exists stably after thermal imidization, so that the $\mathrm{NH}_{2}$-rGO and PI are connected through $\mathrm{C}-\mathrm{N}-\mathrm{C}$ bonds, which improves the interfaces between $\mathrm{NH}_{2}-\mathrm{rGO}$ and $\mathrm{PI}$ and reduces the phonon vibration harmonic mismatch, acoustic mismatch, and modulus mismatch. The scattering degree of phonon at the interfaces is weakened, the mean free path of phonon is increased, and the ITR is reduced, which is beneficial for the efficient improvement of the $\lambda$ of the $\mathrm{NH}_{2}-\mathrm{rGO} / \mathrm{PI}$ thermally conductive composite films.

Figures 5(a) and 5(b) show the relationship between $\lambda_{\|}$, $\lambda_{\perp}$ of the $\mathrm{rGO} / \mathrm{PI}$ and $\mathrm{NH}_{2}$-rGO/PI thermally conductive composite films vs. the amount of thermally conductive fillers (rGO or $\mathrm{NH}_{2}-\mathrm{rGO}$ ). Both the $\lambda_{\|}$and $\lambda_{\perp}$ of the $\mathrm{rGO} / \mathrm{PI}$ and $\mathrm{NH}_{2}$-rGO/PI thermally conductive composite films increase with the increase of the amount of $\mathrm{rGO}$ or $\mathrm{NH}_{2}$ rGO. When the amount of $\mathrm{NH}_{2}-\mathrm{rGO}$ is $15 \mathrm{wt} \%$, the $\lambda_{\|}$and $\lambda_{\perp}$ of the $\mathrm{NH}_{2}-\mathrm{rGO} / \mathrm{PI}$ thermally conductive composite films are $7.13 \mathrm{~W} / \mathrm{mK}$ and $0.74 \mathrm{~W} / \mathrm{mK}$, respectively, which are 8.2 times $\lambda_{\|}(0.87 \mathrm{~W} / \mathrm{mK})$ and 3.5 times $\lambda_{\perp}(0.21 \mathrm{~W} / \mathrm{mK})$ of pure PI film, also higher than the $\lambda_{\|}(5.50 \mathrm{~W} / \mathrm{mK})$ and $\lambda_{\perp}$
$(0.62 \mathrm{~W} / \mathrm{mK})$ of the $\mathrm{rGO} / \mathrm{PI}$ thermally conductive composite films under the same amount of fillers. It can also be seen that the $\lambda$ of thermally conductive PI-based composite films presents obvious anisotropy as $\lambda_{\|}$is greatly higher than $\lambda_{\perp}$. This is attributed to two aspects. One is that the phonon velocity and mean free path along the molecular chains are higher than those between adjacent chains, and the molecular chains in the PI films tend to orient along the in-plane direction of the PI films, so that the $\lambda$ of pure PI films is anisotropic. The second reason is that the blade-coating process makes the $\mathrm{rGO}$ or $\mathrm{NH}_{2}$-rGO orient along the in-plane direction of the PI films, so that the number of thermal conduction pathways in the in-plane direction is far more than that in the vertical direction, further making $\lambda_{\|}$higher than $\lambda_{\perp}$. In addition, under the same amount of rGO and $\mathrm{NH}_{2}-\mathrm{rGO}$, both the $\lambda_{\|}$and $\lambda_{\perp}$ of the $\mathrm{NH}_{2}-\mathrm{rGO} / \mathrm{PI}$ thermally conductive composite films are higher than those of the $\mathrm{rGO} / \mathrm{PI}$ thermally conductive composite films. This is due to the optimization of interfaces between $\mathrm{NH}_{2}$-rGO and $\mathrm{PI}$ that greatly improves the interface compatibility and reduces the ITR and phonon scattering. In addition, the amination is also conducive to the uniform dispersion of $\mathrm{NH}_{2}-\mathrm{rGO}$ in the PI matrix and is conducive to the formation of more thermal conduction pathways, so that the $\lambda$ of $\mathrm{NH}_{2}-\mathrm{rGO} / \mathrm{PI}$ thermally conductive composite films can be quickly and efficiently improved by adding only a few amount of fillers.

In order to further illustrate the effect of the amination on optimizing the interfaces and reducing the ITR, an improved effective medium theory (EMT) model (Equations (2)-(5)) [48] is utilized to calculate ITR between the thermally conductive fillers ( $\mathrm{rGO}$ or $\mathrm{NH}_{2}-\mathrm{rGO}$ ) and the PI matrix in the thermally conductive composite films. 

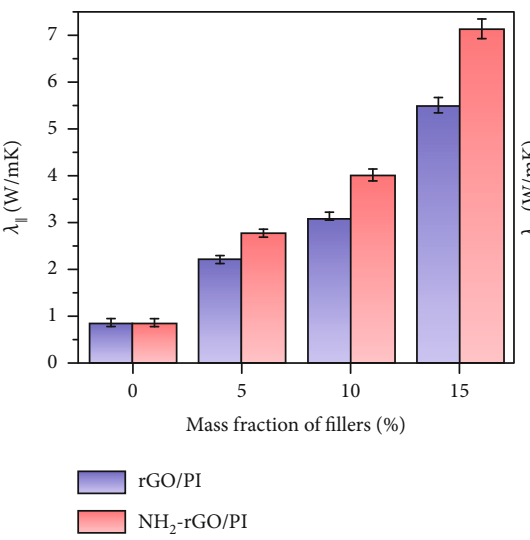

(a)

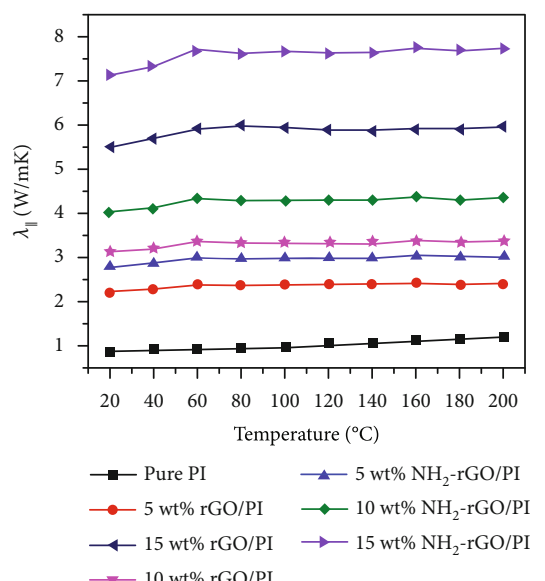

(d)

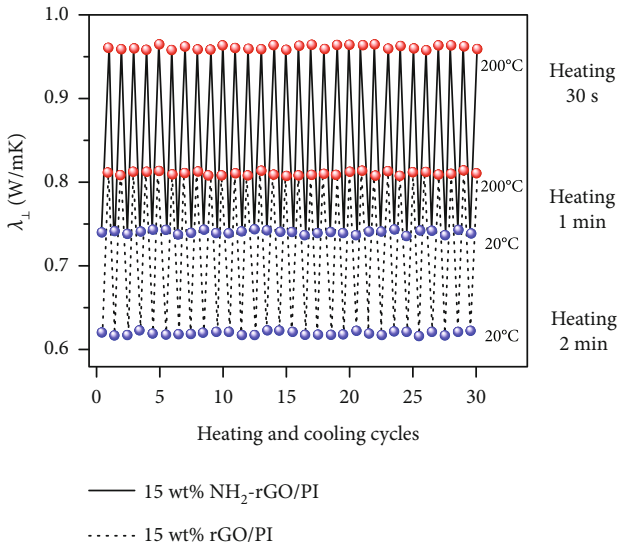

(g)

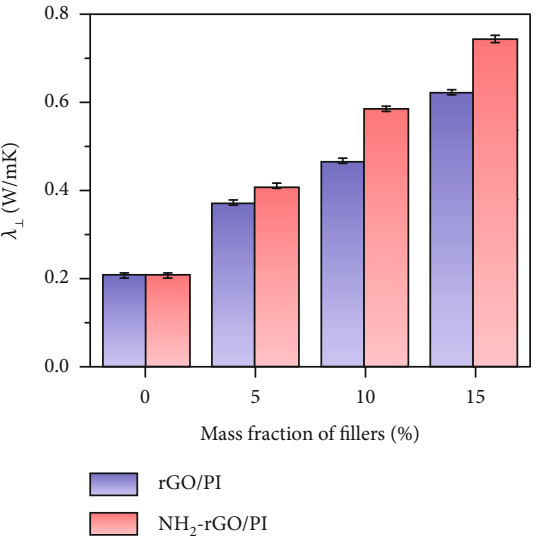

(b)

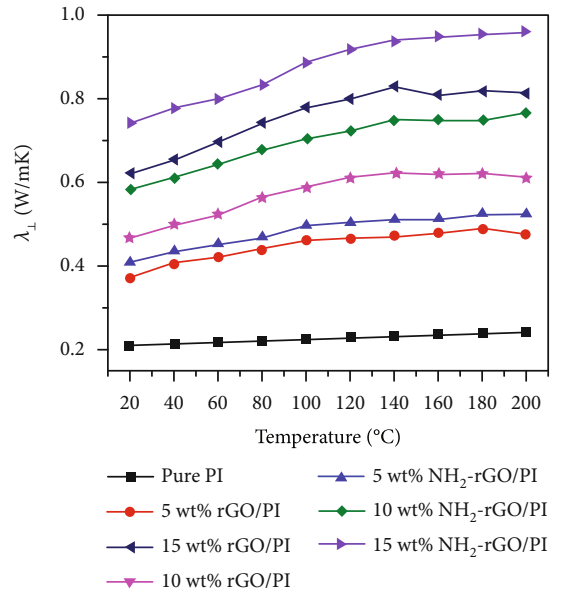

(e)

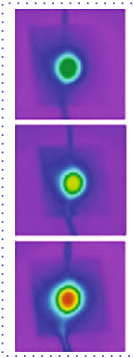

Pure PI

Par

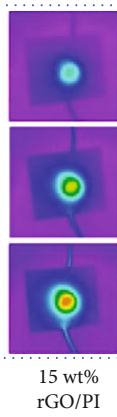

(h)

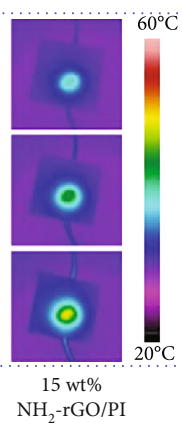

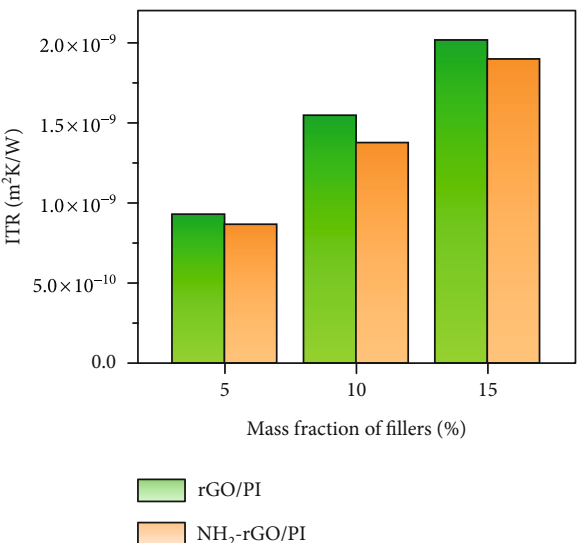

(c)

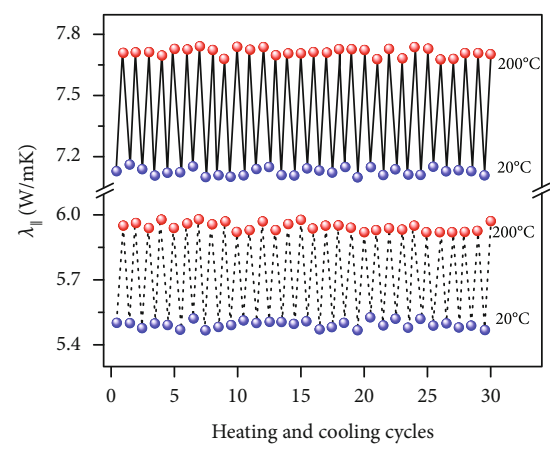

$-15 \mathrm{wt} \% \mathrm{NH}_{2}-\mathrm{rGO} / \mathrm{PI}$

…. $15 \mathrm{wt} \% \mathrm{rGO} / \mathrm{PI}$

(f)

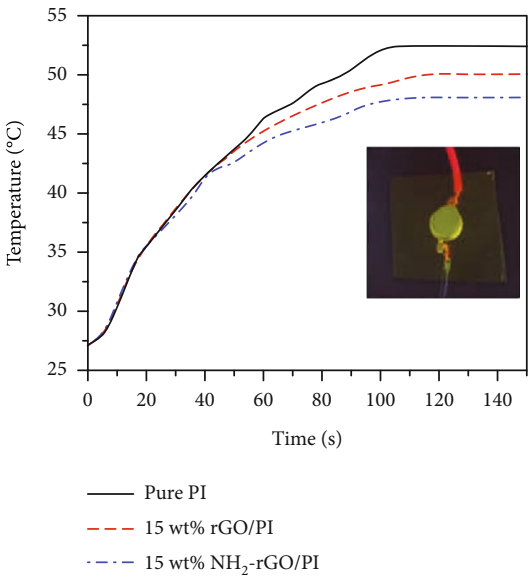

(i)

FIGURE 5: Relationship between $\lambda_{\|}$(a) and $\lambda_{\perp}$ (b) of rGO/PI and $\mathrm{NH}_{2}-\mathrm{rGO} / \mathrm{PI}$ thermally conductive composite films vs. fillers' mass fraction. Calculated ITR between fillers and PI matrix in rGO/PI and $\mathrm{NH}_{2}-\mathrm{rGO} / \mathrm{PI}$ thermally conductive composite films (c). Relationship between $\lambda_{\|}$ (d) and $\lambda_{\perp}$ (e) of rGO/PI and $\mathrm{NH}_{2}$-rGO/PI thermally conductive composite films vs. temperature. $\lambda_{\|}$(f) and $\lambda_{\perp}$ (g) of $15 \mathrm{wt} \% \mathrm{rGO} / \mathrm{PI}$ and $15 \mathrm{wt} \% \mathrm{NH}_{2}$-rGO/PI thermally conductive composite films during 30 heating and cooling cycles. Infrared thermal images of pure PI film, $15 \mathrm{wt} \% \mathrm{rGO} / \mathrm{PI}$, and $\mathrm{NH}_{2}$-rGO/PI thermally conductive composite films (h) and corresponding record of temperature rising ((i), with insert photograph of actual assembly of LED bulb and thermally conductive films). 


$$
\lambda_{\|}=\lambda_{m} \frac{2+V_{f}\left(\lambda_{f} / \lambda_{m}\right)\left(1+\left\langle\cos ^{2} \theta\right\rangle\right)}{2-V_{f}\left(\left(\lambda_{p} H-\lambda_{m} H-R \lambda_{f} \lambda_{m}\right) /\left(\lambda_{f} H\right)\right)\left(1-\left\langle\cos ^{2} \theta\right\rangle\right)},
$$

$\lambda_{\perp}=\lambda_{m} \frac{1+V_{f}\left(\lambda_{f} / \lambda_{m}\right)\left(1-\left\langle\cos ^{2} \theta\right\rangle\right)}{1-V_{f}\left(\left(\lambda_{f} H\right) /\left(H+R \lambda_{f}\right)\right)\left\langle\cos ^{2} \theta\right\rangle}$,

$\left\langle\cos ^{2} \theta\right\rangle=\frac{\int \rho(\theta) \cos ^{2} \theta \sin \theta d \theta}{\int \rho(\theta) \sin \theta d \theta}$,

Among them, $\lambda_{m}$ is the $\lambda$ of the polymer matrix, $\lambda_{f}$ is the $\lambda$ of the thermally conductive fillers, $V_{f}$ is the volume fraction of the thermally conductive fillers, $\theta$ is the angle formed by the orientation direction of the thermally conductive fillers and the in-plane direction of the PI films, $H$ is the thickness of the thermally conductive fillers, and $R$ is the ITR. When the thermally conductive two-dimensional fillers are completely oriented along the in-plane direction of the PI-based composite films, that is, when $\theta=0$, the model can be simplified as Equation (5):

$$
R=\left(\frac{V_{f} \lambda_{\perp}}{\lambda_{\perp}-\lambda_{m}}-\frac{1}{\lambda_{f}}\right) H .
$$

Figure 5(c) exhibits the calculated relationship between the ITR of $\mathrm{rGO} / \mathrm{PI}$ and $\mathrm{NH}_{2}$-rGO/PI thermally conductive composite films vs. the amount of thermally conductive fillers ( $\mathrm{rGO}$ or $\mathrm{NH}_{2}-\mathrm{rGO}$ ). The ITR of the thermally conductive PI-based composite films increases with the increase of the amount of $\mathrm{rGO}$ or $\mathrm{NH}_{2}-\mathrm{rGO}$, which is due to the increase of the interfacial areas between $\mathrm{rGO}$ (or $\mathrm{NH}_{2}-\mathrm{rGO}$ ) and PI matrix. In addition, under the same amount of thermally conductive fillers, the ITR in the $\mathrm{NH}_{2}-\mathrm{rGO} / \mathrm{PI}$ thermally conductive composite films are lower than those of the rGO/PI thermally conductive composite films. For instance, when the amount of $\mathrm{NH}_{2}-\mathrm{rGO}$ is $15 \mathrm{wt} \%$, the corresponding ITR of $\mathrm{NH}_{2}$-rGO/PI thermally conductive composite films is only $1.90 \times 10^{-9} \mathrm{~m}^{2} \mathrm{~K} / \mathrm{W}$, lower than that in $\mathrm{rGO} / \mathrm{PI}$ thermally conductive composite films $\left(2.02 \times 10^{-9} \mathrm{~m}^{2} \mathrm{~K} / \mathrm{W}\right)$.

Furthermore, the influence of ambient temperature on the $\lambda$ of thermally conductive PI-based composite films is also studied. Figures 5(d) and 5(e) show the relationship between $\lambda_{\|}, \lambda_{\perp}$ of the $\mathrm{rGO} / \mathrm{PI}$ and $\mathrm{NH}_{2}$-rGO/PI thermally conductive composite films vs. ambient temperature. Both the $\lambda_{\|}$and $\lambda_{\perp}$ of the pure PI films increase slowly with the increase of ambient temperature, but the increase rate is small. The $\lambda_{\|}$and $\lambda_{\perp}$ of the pure PI films at $200^{\circ} \mathrm{C}$ are $1.19 \mathrm{~W} / \mathrm{mK}$ and $0.24 \mathrm{~W} / \mathrm{mK}$, respectively. With the increase of the amount of thermally conductive fillers $\left(\mathrm{rGO}\right.$ or $\mathrm{NH}_{2}-$ rGO), the increase rate of $\lambda_{\|}$and $\lambda_{\perp}$ with the increase of ambient temperature gradually increases. The $\lambda_{\|}$and $\lambda_{\perp}$ of the $\mathrm{rGO} / \mathrm{PI}$ thermally conductive composite films at $200^{\circ} \mathrm{C}$ are $5.95 \mathrm{~W} / \mathrm{mK}$ and $0.81 \mathrm{~W} / \mathrm{mK}$, respectively, and those of the $\mathrm{NH}_{2}-\mathrm{rGO} / \mathrm{PI}$ thermally conductive composite films are $7.71 \mathrm{~W} / \mathrm{mK}$ and $0.96 \mathrm{~W} / \mathrm{mK}$, respectively. This is mainly because the increase in the ambient temperature enhances the vibration of the crystal lattice, increases the velocity of the phonon, and then improves their $\lambda$. Figures 5(f) and $5(\mathrm{~g})$ show the $\lambda_{\|}$and $\lambda_{\perp}$ of $15 \mathrm{wt} \% \mathrm{rGO} / \mathrm{PI}$ and $15 \mathrm{wt} \%$ $\mathrm{NH}_{2}-\mathrm{rGO} / \mathrm{PI}$ thermally conductive composite films during 30 cooling and heating cycles. At the same temperature during the cooling and heating cycles, the difference in $\lambda$ of the same PI-based composite films in the same direction does not exceed $0.03 \mathrm{~W} / \mathrm{mK}$, indicating the excellent stability of $\lambda$ of thermally conductive PI-based composite films during cooling and heating cycles.

Next, the actual heat dissipation test of the thermally conductive PI-based composite films is conducted. Silica gel is used as the adhesive, thermally conductive PI-based composite films are pasted on the bottom of a LED bulb, and the LED bulb will continue to work for a period of time under the voltage of $3 \mathrm{~V}$. An infrared thermal thermography is used to monitor the temperature changes at the surface of the thermally conductive PI-based composite films. Figure 5(h) exhibits the infrared thermal images of pure PI film, $15 \mathrm{wt} \%$ $\mathrm{rGO} / \mathrm{PI}$, and $15 \mathrm{wt} \% \mathrm{NH}_{2}$-rGO/PI thermally conductive composite films. Figure 5(i) shows the temperature rise curves of those films, in which the inset figure shows the actual assembly of the device. When the LED bulb starts to work, the temperatures of the thermally conductive PIbased composite films gradually rise. Among them, the heat generates most quickly on the pure PI film and the most slowly for $15 \mathrm{wt} \% \mathrm{NH}_{2}$-rGO/PI thermally conductive composite films. When the temperatures are stable, the pure PI film has the highest surface temperature $\left(52.4^{\circ} \mathrm{C}\right)$, and $15 \mathrm{wt} \% \mathrm{NH}_{2}$-rGO/PI thermally conductive composite films have the lowest $\left(48.1^{\circ} \mathrm{C}\right)$, which further proves that the $\mathrm{NH}_{2}-\mathrm{rGO} / \mathrm{PI}$ thermally conductive composite films present more excellent heat dissipation and more efficient thermal management capabilities.

Furthermore, the heat dissipation and thermal management capabilities on 5G high-power chips of pure PI film, $15 \mathrm{wt} \% \mathrm{rGO} / \mathrm{PI}$, and $15 \mathrm{wt} \% \mathrm{NH}_{2}$-rGO/PI thermally conductive composite films are simulated through finite element simulation (FES). Figure 6(a) is the schematic diagram of the FES model, where the silicon chip and the aluminum heat sink sandwich a piece of thermally conductive PI-based composite films as the thermal interface materials, which play the role of heat transfer and protecting the chip. Figures 6(b)6(d) show the FES results of pure PI film, $15 \mathrm{wt} \% \mathrm{rGO} / \mathrm{PI}$, and $15 \mathrm{wt} \% \mathrm{NH}_{2}$-rGO/PI thermally conductive composite films. $15 \mathrm{wt} \% \mathrm{NH}_{2}-\mathrm{rGO} / \mathrm{PI}$ thermally conductive composite films have relatively better heat dissipation and thermal management capabilities, and the corresponding highest temperature on the surface of the chip $\left(113.0^{\circ} \mathrm{C}\right)$ is much lower than those of the pure PI film $\left(148.6^{\circ} \mathrm{C}\right)$ and $15 \mathrm{wt} \% \mathrm{rGO} / \mathrm{PI}$ thermally conductive composite films $\left(115.3^{\circ} \mathrm{C}\right)$. The above simulation results prove that the $\mathrm{NH}_{2}$-rGO/PI thermally conductive composite films present more excellent heat dissipation and efficient thermal management capabilities and can meet the heat dissipation requirements of $5 \mathrm{G}$ electronic devices in practical applications.

Figures S2(a) and S2(b) present the tensile stress-strain curves of pure PI film, rGO/PI, and $\mathrm{NH}_{2}$-rGO/PI thermally conductive composite films, respectively. Figures S2(c)-S2(f) 


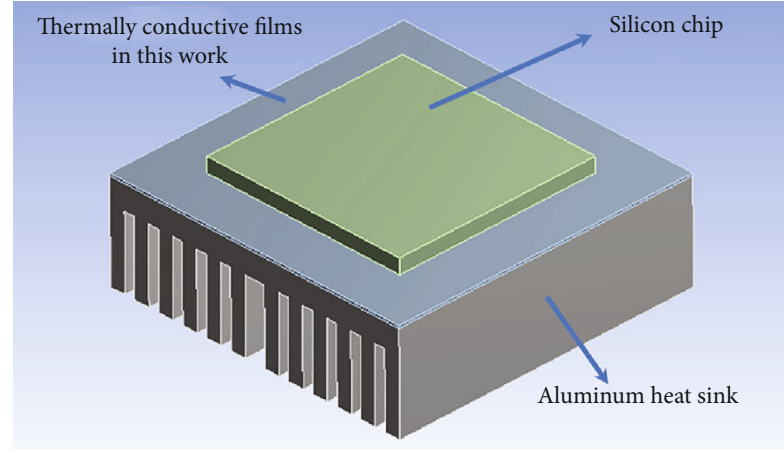

(a)

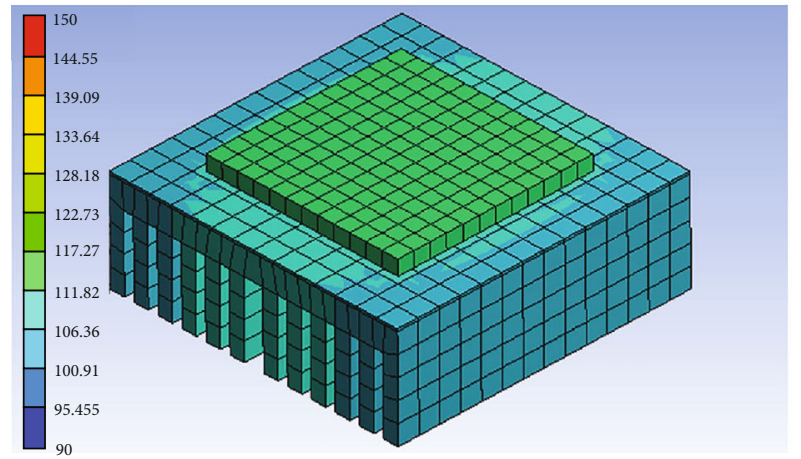

(c)

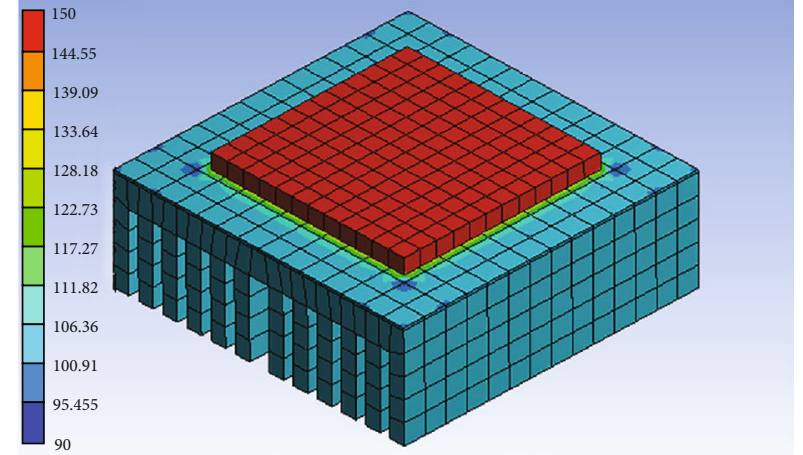

(b)

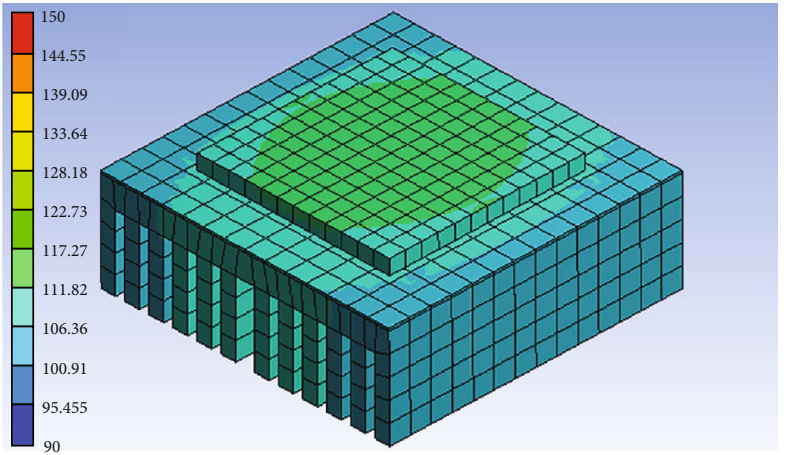

(d)

Figure 6: FES model (a). FES results of pure PI film (b), $15 \mathrm{wt} \% \mathrm{rGO} / \mathrm{PI}$ (c), and $15 \mathrm{wt} \% \mathrm{NH}_{2}$-rGO/PI (d) thermally conductive composite films.

show the relationship between the tensile strength, elongation at break, Young's modulus, and toughness vs. the amount of thermally conductive fillers ( $\mathrm{rGO}$ or $\mathrm{NH}_{2}$-rGO). The tensile strength of the pure PI film is $70.1 \mathrm{MPa}$, and the corresponding elongation at break, Young's modulus, and toughness are $6.45 \%, 1.09 \mathrm{GPa}$, and $2.56 \mathrm{MJ} / \mathrm{m}^{3}$, respectively. With the introduction of $\mathrm{rGO}$ or $\mathrm{NH}_{2}-\mathrm{rGO}$, the Young's modulus of the thermally conductive PI-based composite films gradually increase, due to the effective transfer of part tensile stress in the thermally conductive PI-based composite films to the overall composite networks. But the tensile strength, elongation at break, and toughness of the thermally conductive PI-based composite films gradually decrease, due to that the introduction of $\mathrm{rGO}$ or $\mathrm{NH}_{2}$-rGO causes some defects in the thermally conductive PI-based composite films. It should be noted that, under the same amount of rGO and $\mathrm{NH}_{2}-\mathrm{rGO}$, the tensile strength, Young's modulus, and toughness of $\mathrm{NH}_{2}-\mathrm{rGO} / \mathrm{PI}$ thermally conductive composite films are all significantly higher than rGO/PI thermally conductive composite films. For example, the tensile strength, Young's modulus, and toughness of $15 \mathrm{wt} \%$ $\mathrm{NH}_{2}$-rGO/PI thermally conductive composite films reached 35.7 $\mathrm{MPa}, 2.04 \mathrm{GPa}$, and $0.322 \mathrm{MJ} / \mathrm{m}^{3}$, respectively, which are, respectively, $15.4 \%, 16.2 \%$, and $11.8 \%$ higher than the tensile strength $(30.2 \mathrm{MPa})$, Young's modulus $(1.71 \mathrm{GPa})$, and toughness $\left(0.284 \mathrm{MJ} / \mathrm{m}^{3}\right)$ of $15 \mathrm{wt} \% \mathrm{rGO} / \mathrm{PI}$ thermally conductive composite films. This is because $\mathrm{NH}_{2}-\mathrm{rGO}$ and PI matrix are connected by C-N-C bonds, which effectively improves the interfaces. At the same time, $\mathrm{NH}_{2}-\mathrm{rGO}$, as the dispersed phase, enhances the interaction between the two through the sea-island structure and crack anchor effect, reducing sliding of the PI molecular chains in the $\mathrm{NH}_{2}$ rGO/PI thermally conductive composite films during the stretching process, thereby improving the mechanical properties of the $\mathrm{NH}_{2}$-rGO/PI thermally conductive composite films [49]. It is clearly shown that the amination can effectively achieve the synergistic improvement of the $\lambda$ and mechanical properties of the $\mathrm{NH}_{2}-\mathrm{rGO} / \mathrm{PI}$ thermally conductive composite films, both attributed to the optimization of interfaces.

Figures S3(a) and S3(b) show the differential scanning calorimetry (DSC) and TGA curves of the $\mathrm{NH}_{2}$-rGO/PI thermally conductive composite films, respectively, and Table S2 shows the corresponding thermal characteristic data. As the amount of $\mathrm{NH}_{2}-\mathrm{rGO}$ increases, the glass transition temperatures $\left(T_{g}\right)$ of the $\mathrm{NH}_{2}-\mathrm{rGO} / \mathrm{PI}$ thermally conductive composite films gradually rise. When the amount of $\mathrm{NH}_{2}$-rGO is $15 \mathrm{wt} \%$, the corresponding $T_{g}$ of the $\mathrm{NH}_{2}$-rGO/PI thermally conductive composite films increases from $320.2^{\circ} \mathrm{C}$ of pure PI to $337.7^{\circ} \mathrm{C}$. This is because $\mathrm{NH}_{2}$-rGO occupies a certain free volume of $\mathrm{PI}$, and the formation of C-N-C bonds between $\mathrm{NH}_{2}-\mathrm{rGO}$ and PI restricts the movement of PI molecular chains, thereby increasing the $T_{g}$. Meantime, as the amount of $\mathrm{NH}_{2}-\mathrm{rGO}$ increases, the $T_{5}, T_{30}$, and the corresponding heat resistance index $\left(T_{\mathrm{HRI}}\right)$ of the $\mathrm{NH}_{2}-\mathrm{rGO} / \mathrm{PI}$ thermally 
conductive composite films gradually increase, that is, the thermal stability gradually increases. When the amount of $\mathrm{NH}_{2}-\mathrm{rGO}$ is $15 \mathrm{wt} \%$, the $T_{5}, T_{30}$, and $T_{\mathrm{HRI}}$ of the $\mathrm{NH}_{2}-$ $\mathrm{rGO} / \mathrm{PI}$ thermally conductive composite films increase from $510.3^{\circ} \mathrm{C}, 588.7^{\circ} \mathrm{C}$, and $273.1^{\circ} \mathrm{C}$ of pure PI to $522.8^{\circ} \mathrm{C}$, $605.5^{\circ} \mathrm{C}$, and $280.5^{\circ} \mathrm{C}$, respectively. The reason is that $\mathrm{NH}_{2}$-rGO has good interface compatibility with the PI matrix, and it uniformly disperses in the PI matrix and forms a carbon layer network, thus, effectively prevents the exudation of thermal decomposition products. Moreover, as the temperature rises, the PI matrix absorbs heat and pyrolyzes, and the gas product produced escapes into the boundary layer, blocking the heat entering the interior, forming the thermal blocking effect, which is also beneficial for enhancing the thermal stability of the $\mathrm{NH}_{2}-\mathrm{rGO} / \mathrm{PI}$ thermally conductive composite films [50]. It can be deduced that the $\mathrm{NH}_{2}-\mathrm{rGO} / \mathrm{PI}$ thermally conductive composite films possess excellent thermal properties and can be used stably for a long period of time under an environment in high temperature.

\section{Conclusions}

XPS, FTIR, TGA, XRD, Raman, and AFM proved that $\mathrm{NH}_{2}{ }^{-}$ rGO thermally conductive fillers with only a few layers (approximately 4 layers) were successfully prepared. Raman proved that the amination improved the interfaces between $\mathrm{NH}_{2}$-rGO fillers and PI matrix and reduced the phonon scattering at the interfaces as well as the ITR. The fabricated $\mathrm{NH}_{2}$-rGO/PI thermally conductive composite films present excellent $\lambda$, ideal mechanical properties, and outstanding thermal stability. When the amount of $\mathrm{NH}_{2}-\mathrm{rGO}$ was $15 \mathrm{wt} \%$, the corresponding $\lambda_{\|}$and $\lambda_{\perp}$ of the $\mathrm{NH}_{2}$-rGO/PI thermally conductive composite films at room temperature reached $7.13 \mathrm{~W} / \mathrm{mK}$ and $0.74 \mathrm{~W} / \mathrm{mK}$, respectively, 8.2 times $\lambda_{\|}(0.87 \mathrm{~W} / \mathrm{mK})$ and 3.5 times $\lambda_{\perp}(0.21 \mathrm{~W} / \mathrm{mK})$ of pure PI film, also significantly higher than $\lambda_{\|}(5.50 \mathrm{~W} / \mathrm{mK})$ and $\lambda_{\perp}$ $(0.62 \mathrm{~W} / \mathrm{mK})$ of $15 \mathrm{wt} \% \mathrm{rGO} / \mathrm{PI}$ thermally conductive composite films. Calculation based on the EMT model proved that ITR was reduced via amination. Infrared thermal imaging and FES showed that $\mathrm{NH}_{2}-\mathrm{rGO} / \mathrm{PI}$ thermally conductive composite films presented excellent heat dissipation and efficient thermal management capabilities on LED bulbs, 5G high-power chips, and other electronic equipment, which are easy to generate heat severely. Meanwhile, the tensile strength, Young's modulus, and toughness of the $15 \mathrm{wt} \%$ $\mathrm{NH}_{2}$-rGO/PI thermally conductive composite films reached 35.7 MPa, 2.04 GPa, and $0.322 \mathrm{MJ} / \mathrm{m}^{3}$, and its $T_{g}$ and $T_{\text {HRI }}$ also increased to $337.7^{\circ} \mathrm{C}$ and $280.5^{\circ} \mathrm{C}$ from $320.2^{\circ} \mathrm{C}$ and $273.1^{\circ} \mathrm{C}$ of pure $\mathrm{PI}$, respectively.

\section{Materials and Methods}

Experimental details including main materials, preparation of $\mathrm{NH}_{2}$-rGO thermally conductive fillers, fabrication of $\mathrm{NH}_{2}$-rGO/PI thermally conductive composite films, and characterizations can be found in the Supplementary 1.

\section{Data Availability}

The data in this paper cannot be shared at this time as the data also forms part of an ongoing study.

\section{Conflicts of Interest}

The authors declare that there are no conflicts of interest regarding the publication of this article.

\section{Authors' Contributions}

J. Gu conceived and supervised the project. K. Ruan and Y. Guo prepared $\mathrm{NH}_{2}$-rGO thermally conductive fillers and fabricated $\mathrm{NH}_{2}$-rGO/PI thermally conductive composite films. K. Ruan, C. Lu, and X. Shi characterized $\mathrm{NH}_{2}-\mathrm{rGO}$ thermally conductive fillers by XPS, FTIR, TGA, Raman spectroscopy, XRD, and AFM. K. Ruan and Y. Zhang performed Raman spectroscopy on interfaces in $\mathrm{NH}_{2}$-rGO/PI thermally conductive composite films as well as SEM and analyzed the data. K. Ruan and T. Ma tested the thermal conduction properties of $\mathrm{NH}_{2}-\mathrm{rGO} / \mathrm{PI}$ thermally conductive composite films. K. Ruan and J. Kong characterized the mechanical and thermal properties of $\mathrm{NH}_{2}$-rGO/PI thermally conductive composite films. K. Ruan, Y. Guo, C. Lu, X. Shi, T. Ma, Y. Zhang, J. Kong, and J. Gu cowrote the manuscript. All authors discussed the results and commented on the manuscript.

\section{Acknowledgments}

The authors are grateful for the support and funding from the National Natural Science Foundation of China (51973173 and 51773169) and the Natural Science Basic Research Plan for Distinguished Young Scholars in Shaanxi Province of China (2019JC-11). Y.Q. Guo thanks for the Innovation Foundation for Doctor Dissertation of Northwestern Polytechnical University (CX202055). C.Y. Lu thanks for the Undergraduate Innovation \& Business Program in Northwestern Polytechnical University (S202010699141). This work is also financially supported by the Polymer Electromagnetic Functional Materials Innovation Team of Shaanxi Sanqin Scholars. We would like to thank the Analytical \& Testing Center of Northwestern Polytechnical University for AFM, Raman spectra, and SEM tests.

\section{Supplementary Materials}

Supplementary 1. S1: Experimental Section: S1.1 Main Materials, S1.2 Preparation of $\mathrm{NH}_{2}$-rGO Thermally Conductive Fillers, S1.3 Fabrication of $\mathrm{NH}_{2}-\mathrm{rGO} / \mathrm{PI}$ Thermally Conductive Composite Films, S1.4 Characterizations. S2: Supporting Results: Figure S1: SEM images of cross-sections for pure PI film (a), 15 wt $\%$ rGO/PI (b), and 15 wt $\% \mathrm{NH}_{2}-\mathrm{rGO} / \mathrm{PI}$ (c) thermally conductive composite films; Figure S2: Stressstrain curves of rGO/PI (a) and $\mathrm{NH}_{2}-\mathrm{rGO} / \mathrm{PI}$ (b) thermally conductive composite films. Relationship between tensile strength (c), elongation at break (d), Young's modulus (e), and toughness (f) of thermally conductive PI-based composite films vs. fillers' mass fraction. Figure S3: DSC (a) and TGA 
(b) curves of $\mathrm{NH}_{2}-\mathrm{rGO} / \mathrm{PI}$ thermally conductive composite films. Table S1: Molar fraction of surface elements and carbon/oxygen $(\mathrm{C} / \mathrm{O})$ atomic ratio for GNPs, $\mathrm{GO}, \mathrm{NH}_{2^{-}}$ $\mathrm{GO}$, and $\mathrm{NH}_{2}-\mathrm{rGO}$.Table S2: Thermal characteristic data of the $\mathrm{NH}_{2}-\mathrm{rGO} / \mathrm{PI}$ thermally conductive composite films. (Supplementary Materials)

\section{References}

[1] S. Li, Q. Zheng, Y. Lv et al., "High thermal conductivity in cubic boron arsenide crystals," Science, vol. 361, no. 6402, pp. 579-581, 2018.

[2] X. Xu, J. Chen, J. Zhou, and B. Li, "Thermal conductivity of polymers and their nanocomposites," Advanced Materials, vol. 30, no. 17, article 1705544, 2018.

[3] F. Tian and Z. Ren, "High thermal conductivity in boron arsenide: from prediction to reality," Angewandte ChemieInternational Edition, vol. 58, no. 18, pp. 5824-5831, 2019.

[4] J. Chen, X. Huang, B. Sun, and P. Jiang, "Highly thermally conductive yet electrically insulating polymer/boron nitride nanosheets nanocomposite films for improved thermal management capability," ACS Nano, vol. 13, pp. 337-345, 2018.

[5] D. J. Liaw, K. L. Wang, Y. C. Huang, K. R. Lee, J. Y. Lai, and C. S. Ha, "Advanced polyimide materials: syntheses, physical properties and applications," Progress in Polymer Science, vol. 37, no. 7, pp. 907-974, 2012.

[6] Y. Guo, G. Xu, X. Yang et al., "Significantly enhanced and precisely modeled thermal conductivity in polyimide nanocomposites with chemically modified graphenevia in situpolymerization and electrospinning-hot press technology," Journal of Materials Chemistry C, vol. 6, no. 12, pp. 3004-3015, 2018.

[7] H. Li, S. Dai, J. Miao et al., "Enhanced thermal conductivity of graphene/polyimide hybrid film via a novel "molecular welding" strategy," Carbon, vol. 126, pp. 319-327, 2018.

[8] X. Huang, C. Zhi, Y. Lin et al., "Thermal conductivity of graphene-based polymer nanocomposites," Materials Science and Engineering: R: Reports, vol. 142, article 100577, 2020.

[9] A. A. Tarhini and A. R. Tehrani-Bagha, "Graphene-based polymer composite films with enhanced mechanical properties and ultra-high in-plane thermal conductivity," Composites Science and Technology, vol. 184, article 107797, 2019.

[10] Y. Li, Z. Cao, T. Li et al., "Highly selective biomimetic flexible tactile sensor for neuroprosthetics," Research, vol. 2020, article 8910692, 11 pages, 2020.

[11] C. Zhu, R. Li, X. Chen et al., "Ultraelastic yarns from curcumin-assisted ELD toward wearable human-machine interface textiles," Advanced Science, vol. 7, no. 23, 2020.

[12] M. H. Tsai, I. H. Tseng, J. C. Chiang, and J. J. Li, "Flexible polyimide films hybrid with functionalized boron nitride and graphene oxide simultaneously to improve thermal conduction and dimensional stability," ACS Applied Materials \& Interfaces, vol. 6, no. 11, pp. 8639-8645, 2014.

[13] W. Yan, Y. Zhang, H. Sun et al., "Polyimide nanocomposites with boron nitride-coated multi-walled carbon nanotubes for enhanced thermal conductivity and electrical insulation," Journal of Materials Chemistry A, vol. 2, no. 48, pp. 2095820965, 2014.

[14] G. H. Hwang, Y. S. Kwon, J. S. Lee, and Y. G. Jeong, "Enhanced mechanical and anisotropic thermal conductive properties of polyimide nanocomposite films reinforced with hexagonal boron nitride nanosheets," Journal of Applied Polymer Science, no. article e50324, 2020.

[15] Z. He, W. Dai, J. Yu et al., "Enhanced thermal and mechanical properties of polyimide composites by mixing thermotropic liquid crystalline epoxy grafted aluminum nitride," Journal of Polymer Research, vol. 21, no. 11, p. 595, 2014.

[16] Y. Wang, X. Zhang, X. Ding et al., "Imidization-induced carbon nitride nanosheets orientation towards highly thermally conductive polyimide film with superior flexibility and electrical insulation," Composites Part B: Engineering, vol. 199, article 108267, 2020.

[17] H. Song, B. G. Kim, Y. S. Kim, Y. S. Bae, J. Kim, and Y. Yoo, "Synergistic effects of various ceramic fillers on thermally conductive polyimide composite films and their model predictions," Polymers, vol. 11, no. 3, p. 484, 2019.

[18] S. Wei, Q. Yu, Z. Fan et al., "Fabricating high thermal conductivity $\mathrm{rGO}$ /polyimide nanocomposite filmsviaa freeze-drying approach," RSC Advances, vol. 8, no. 39, pp. 22169-22176, 2018.

[19] J. Gong, Z. Liu, J. Yu et al., “Graphene woven fabric-reinforced polyimide films with enhanced and anisotropic thermal conductivity," Composites Part A-Applied Science and Manufacturing, vol. 87, pp. 290-296, 2016.

[20] J. Chen, H. Wei, H. Bao, P. Jiang, and X. Huang, "Millefeuilleinspired thermally conductive polymer nanocomposites with overlapping $\mathrm{BN}$ nanosheets for thermal management applications," ACS Applied Materials \& Interfaces, vol. 11, no. 34, pp. 31402-31410, 2019.

[21] Y. Li, C. Gong, C. Li et al., "Liquid crystalline texture and hydrogen bond on the thermal conductivities of intrinsic thermal conductive polymer films," Journal of Materials Science of Technology, vol. 82, pp. 250-256, 2021.

[22] R. J. Stevens, L. V. Zhigilei, and P. M. Norris, "Effects of temperature and disorder on thermal boundary conductance at solid- solid interfaces: Nonequilibrium molecular dynamics simulations," International Journal of Heat and Mass Transfer, vol. 50, no. 19-20, pp. 3977-3989, 2007.

[23] K. Ruan, X. Shi, Y. Guo, and J. Gu, "Interfacial thermal resistance in thermally conductive polymer composites: a review," Composites Communications, vol. 22, article 100518, 2020.

[24] F. Lv, M. Qin, F. Zhang et al., "High cross-plane thermally conductive hierarchical composite using graphene- coated vertically aligned carbon nanotubes/graphite," Carbon, vol. 149, pp. 281-289, 2019.

[25] X. Shi, R. Zhang, K. Ruan, T. Ma, Y. Guo, and J. Gu, "Improvement of thermal conductivities and simulation model for glass fabrics reinforced epoxy laminated composites via introducing hetero-structured [email protected] fillers," Journal of Materials Science \& Technology, vol. 82, pp. 239-249, 2021.

[26] Z. G. Wang, Y. L. Yang, Z. L. Zheng et al., “Achieving excellent thermally conductive and electromagnetic shielding performance by nondestructive functionalization and oriented arrangement of carbon nanotubes in composite films," Composites Science and Technology, vol. 194, article 108190, 2020.

[27] A. Shi, Y. Li, W. Liu et al., "Highly thermally conductive and mechanically robust composite of linear ultrahigh molecular weight polyethylene and boron nitride via constructing nacre-like structure," Composites Science and Technology, vol. 184, article 107858, 2019.

[28] I. H. Tseng, J. C. Chang, S. L. Huang, and M. H. Tsai, "Enhanced thermal conductivity and dimensional stability of 
flexible polyimide nanocomposite film by addition of functionalized graphene oxide," Polymer International, vol. 62, no. 5, pp. 827-835, 2013.

[29] T. Ma, Y. Zhao, K. Ruan et al., "Highly thermal conductivities, excellent mechanical robustness and flexibility, and outstanding thermal stabilities of aramid nanofiber composite papers with nacre-mimetic layered structures," ACS Applied Materials \& Interfaces, vol. 12, pp. 1677-1686, 2019.

[30] Y. Wu, K. Ye, Z. Liu et al., "Cotton candy-templated fabrication of three-dimensional ceramic pathway within polymer composite for enhanced thermal conductivity," ACS Applied Materials \& Interfaces, vol. 11, no. 47, pp. 44700-44707, 2019.

[31] Y. Chen, X. Hou, M. Liao et al., "Constructing a "pea-pod-like" alumina-graphene binary architecture for enhancing thermal conductivity of epoxy composite," Chemical Engineering Journal, vol. 381, article 122690, 2020.

[32] F. Zhang, Y. Y. Feng, and W. Feng, "Three-dimensional interconnected networks for thermally conductive polymer composites: design, preparation, properties, and mechanisms," Materials Science and Engineering: R: Reports, vol. 142, article 100580, 2020.

[33] J. B. Wu, M. L. Lin, X. Cong, H. N. Liu, and P. H. Tan, "Raman spectroscopy of graphene-based materials and its applications in related devices," Chemical Society Reviews, vol. 47, no. 5, pp. 1822-1873, 2018.

[34] W. Zhao, W. Chen, Y. Yue, and S. Wu, "In-situ two-step Raman thermometry for thermal characterization of monolayer graphene interface material," Applied Thermal Engineering, vol. 113, pp. 481-489, 2017.

[35] X. F. Yue, Y. Y. Wang, Y. Zhao et al., "Measurement of interfacial thermal conductance of few-layer MoS2supported on different substrates using Raman spectroscopy," Journal of Applied Physics, vol. 127, no. 10, article 104301, 2020.

[36] L. Qiu, H. Zou, X. Wang et al., "Enhancing the interfacial interaction of carbon nanotubes fibers by Au nanoparticles with improved performance of the electrical and thermal conductivity," Carbon, vol. 141, pp. 497-505, 2019.

[37] J. Liu, H. Wang, W. Ma, X. Zhang, and Y. Song, "Simultaneous measurement of thermal conductivity and thermal contact resistance of individual carbon fibers using Raman spectroscopy," Review of Scientific Instruments, vol. 84, no. 4, article 044901, 2013.

[38] N. Peimyoo, J. Shang, W. Yang, Y. Wang, C. Cong, and T. Yu, "Thermal conductivity determination of suspended monoand bilayer $\mathrm{WS}_{2}$ by Raman spectroscopy," Nano Research, vol. 8, no. 4, pp. 1210-1221, 2015.

[39] Y. Guo, X. Yang, K. Ruan et al., "Reduced graphene oxide heterostructured silver nanoparticles significantly enhanced thermal conductivities in hot-pressed electrospun polyimide nanocomposites," ACS Applied Materials \& Interfaces, vol. 11, no. 28, pp. 25465-25473, 2019.

[40] Y. Guo, K. Ruan, X. Yang et al., "Constructing fully carbonbased fillers with a hierarchical structure to fabricate highly thermally conductive polyimide nanocomposites," Journal of Materials Chemistry C, vol. 7, no. 23, pp. 7035-7044, 2019.

[41] Y. Yao, X. Zeng, F. Wang, R. Sun, J. B. Xu, and C. P. Wong, "Significant enhancement of thermal conductivity in bioinspired freestanding boron nitride papers filled with graphene oxide," Chemistry of Materials, vol. 28, no. 4, pp. 1049-1057, 2016.
[42] L. Ma, Y. Wang, Y. Wang, C. Wang, and X. Gao, "Graphene induced carbonization of polyimide films to prepared flexible carbon films with improving-thermal conductivity," Ceramics International, vol. 46, no. 3, pp. 3332-3338, 2020.

[43] H. Hou, W. Dai, Q. Yan et al., "Graphene size-dependent modulation of graphene frameworks contributing to the superior thermal conductivity of epoxy composites," Journal of Materials Chemistry A, vol. 6, no. 25, pp. 12091-12097, 2018.

[44] M. Qin, Y. Xu, R. Cao, W. Feng, and L. Chen, "Efficiently controlling the $3 \mathrm{D}$ thermal conductivity of a polymer nanocomposite via a hyperelastic double-continuous network of graphene and sponge," Advanced Functional Materials, vol. 28, no. 45, article 1805053, 2018.

[45] A. K. Kadiyala, M. Sharma, and J. Bijwe, "Exploration of thermoplastic polyimide as high temperature adhesive and understanding the interfacial chemistry using XPS, ToFSIMS and Raman spectroscopy," Materials \& Design, vol. 109, pp. 622-633, 2016.

[46] Q. Y. Li, K. Katakami, T. Ikuta, M. Kohno, X. Zhang, and K. Takahashi, "Measurement of thermal contact resistance between individual carbon fibers using a laser-flash Raman mapping method," Carbon, vol. 141, pp. 92-98, 2019.

[47] P. Yuan, R. Wang, H. Tan, T. Wang, and X. Wang, "Energy transport state resolved Raman for probing interface energy transport and hot carrier diffusion in few-layered $\mathrm{MoS}_{2}$," ACS Photonics, vol. 4, no. 12, pp. 3115-3129, 2017.

[48] Z. G. Wang, W. Liu, Y. H. Liu et al., "Highly thermal conductive, anisotropically heat-transferred, mechanically flexible composite film by assembly of boron nitride nanosheets for thermal management," Composites Part B: Engineering, vol. 180, article 107569, 2020.

[49] J. Q. Xie, L. Jiang, J. Chen et al., "NiMn hydroxides supported on porous Ni/graphene films as electrically and thermally conductive electrodes for supercapacitors," Chemical Engineering Journal, vol. 393, article 124598, 2020.

[50] L. Wang, P. Song, C. T. Lin, J. Kong, and J. Gu, “3D shapeable, superior electrically conductive cellulose $\mathrm{Na}$ nofibers/Ti3C2TxMXene aerogels/epoxy nanocomposites for promising EMI shielding," Research, vol. 2020, article 4093732, 12 pages, 2020. 